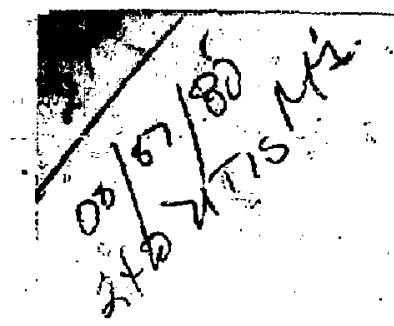

\title{
DYNAVAC: A TRANBIENT-VACUUM-TETWOAK
}

\section{MASTER} ANALYSIS CODE

Gary A. Dets

July 8, 1980

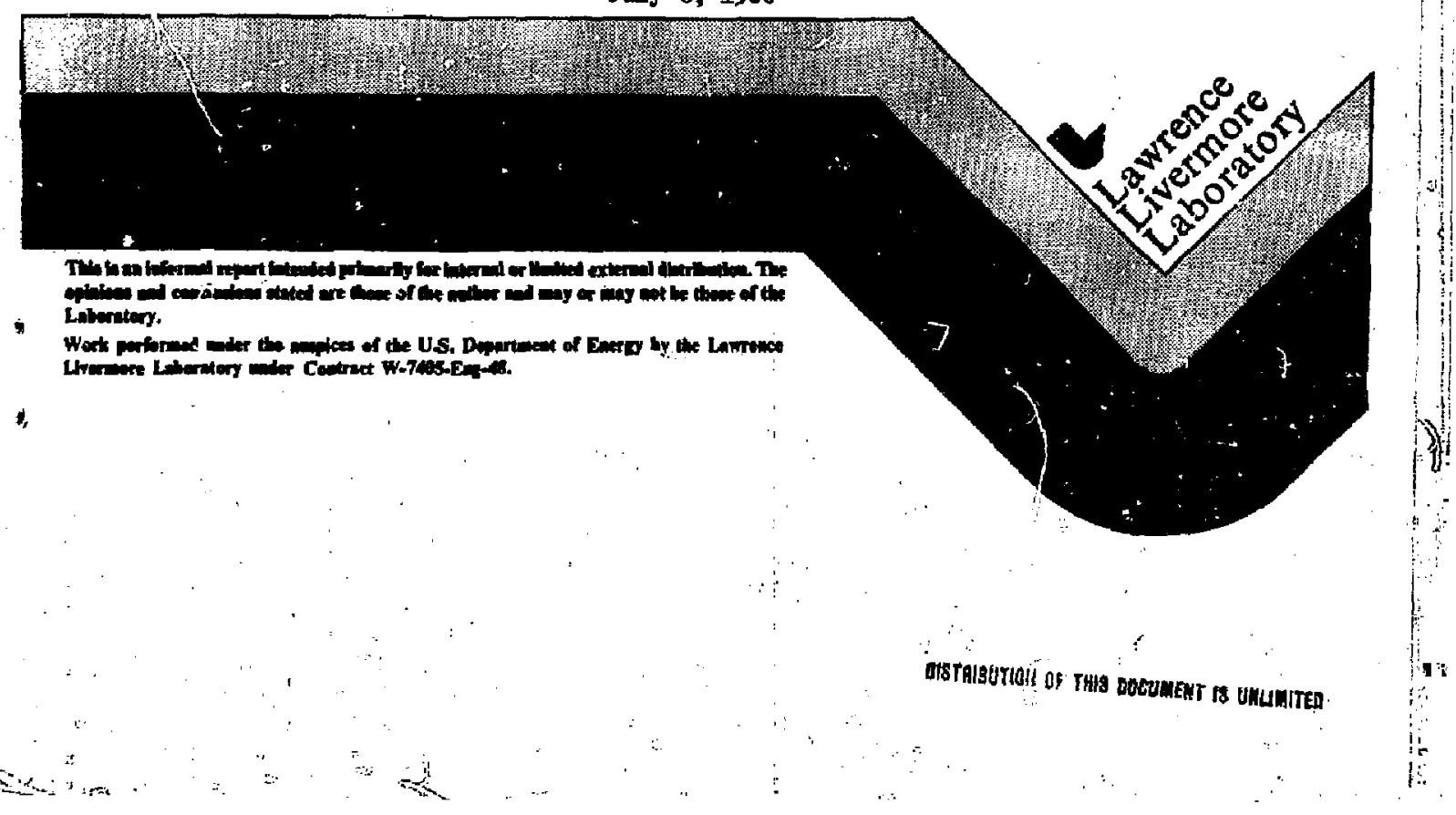




\section{ABSTRACT}

This report discusses the structure and use of the progtam DYNAVAC, a new transient-vacuum-network analysis code implemented on the NMFECC CDC-7600 computer. DYNAVAC solves for the transient pressures in a network of up to twenty lumped volumes, interconnected in any configuration by specified conductances. Each volume can have an internal gas source, a pumping speed, and any initial pressure. The gas-source tates can vary with time in any piecewise-linear manner, and up to twenty different time variations can be included in a single problem. In adoition, the pumping speed in each volume can vary with the total gas pumped in the volume, thus simulating the saturation of surface pumping. This report is intended to be both a general description and a user's manual for DYNAvAC.

\section{INTRODUCTION}

The experimental magnetic fusion energy program frequently presents one with the problem of desianing, for a new experiment, a vacuum system which maintains a low pressure in the vicinity of the plasma while large anounts of gas are being injected into the vacuum via neutral beams and other gas sources. In the past, these design problems have been treated in basically two ways.

The first method is to assume that the vacuum system reaches equilibrium during the physics experiment, and design on that assumption. This has been done most frequently at LLL using the computer code GASBAL, written by Hoffman, Roose, and Carison. 1 GASBAL performs a steady-state solution to obtain the pressures in the various volumes within the system, taking into account the influence of the plasma itself, direct streaming gas from neutral beams, both high and Iow energy gas, and many other factors (more than 28 in all). However,

i. T. R. Roose, M. A. Hoffman, and G. A. Carlson, "Analysis of the Steadystate Operation of Vacuum Systems for Pusion Machines, " in Pzoc. of the sixth Symposium on Engincering Problems of Fusion Research, San Diego, CA, Nov. 18-21, 1975, TEEE Publication number 75CH1097-S-NPS (1976). 
GASBAL assumes a geometry in which pairs of volumes in series radiate out from a single, central, plasme chamber. Although (with some creativity on the part of their deslgners) many systems can be modelled in this general manner, tandem mirrors do not seem to be among them. In addition, experimental information from TMx indicates that the vacuum does not reach equilibrium during the experiment, which means that an assumption of conditions steady-state could lead to over-design of the vacuun system.

A second method of attacking the general problem is by solving the system differential equations manually. If a lumped model is assumed, the equations are straightforward but extremely tedious to solve, especially for large numbers of lumped volumes. Furthermore, in the design process where changes are frequent, wany such solutions (each one different) are required. One tool which is currently available to help in this approach is the computer code DIP3. ${ }^{2}$ This code is an interactive solver for a three-volume, differentialpumping system. The three volumes are required to be in series, and there can be only one gas source, located in the first volume. The output of this code consists of the three pressures and the flow of gas out of the third volume, at requested time steps. DIP3 produces exact results, since it merely supplies the input quantities to an extant general three-volume solution obtained by standaro analytical means. This code has been useful in estimating saturation times for pumping surfaces within vacuum systems. Again, the geometry is restrictive, and although DIP3 is an extremely convenient method for handling simple problems, it cannot be used effectively for large, many-volume systens.

To solve this general vacuum system design problem satisfactorily, a tool is required that provides transient solutions to the general system equations for a large number of volumes, interconnected in any way. It must allow for variations in the properties of the system in order to account for timevariable gas sources and saturation of surface pumping, and it must be coivenient and easy to use. Out of these requirements the code DYNAVAC was created. It has been constructed to be used easily in the design process, just as codes are used for stress, magnetic-fleld, and electric-field design. Purthermore, it is constructer in a modular Eashion which will allow special features to be added as they are required.

2. L. Pittenger, "Analytic Solution for the Transient Response of 3-Stage Differentially-pumped Vacuun Systems in the Molecular Flow Regime," Lawrence Livermore Laboratory Fng ineer ing Note ENE 75-4 (Janjary 1975). 
DYNavac solves the general vacuum-network problem of $N(\leq 20)$ lumped volumes interconnected in any configuration by conductances. In general, each lumped volume has four properties: volume (V), pumping speed (S), gas source rate (Q) and pressure (P). In adaition, each volume can be connected to any other volume via specified conductances, which need not be the same in both directions; that is, the conductance fron volume : to volume $j$ need not be the same as that from volume $j$ to volume $i$. With this information, one aan write the continuity equation for volume $i$, to $y$ ield the general, first order, ordinary differential equatior (ODE) for a volume:

$$
v_{i} \frac{d P_{i}}{d t}=Q_{i}-\operatorname{siPi}-\sum_{j=1}^{\because}\left(c_{i j} P_{L}-c_{j i} P_{j}\right)
$$

where $c_{1 i} \equiv 0$.

This equation indicates simply that the rate of increase of gas in the volume is equal to the rate at wich it is added to the volume by a source within the volume, minus the rate at wich it is pumped within the volume, minus the net rate at which it is conducted away to all other volumes. For a general system of $N$ connected volumes, there are $N$ similar equations, each containing $N$ unknowns, the piessure in each of the volumes.

Within DYNAVAC, this system of first order ODE's is solved by LSODE, a sclver descended from GEAR, and written by Alan C. Hindmarsh. ${ }^{3}$ This powerful ODE solver is flexible enough that variations in the system properties can be made quite easily. For the current version of DYNAVAc, only two such variaticns have been incorporated. The first, time-variable gas source rates, is intended to allow simple simulation of neutral-beam sources and other gas loads, which may increase or decrease during the experiment. the second, variable pumping speeds, is intended to model the saturation effect of pumping surfaces. This is accomplished by permitting the pumping speed in each volume to vary with the total amount of gas pumped in that volume:

3. A. C. Hindmarsh, ISODE-Livermore Solver for Ordinary Differential Eguations, Lawtence Livermore Laboratory report in preparation. 


$$
s_{1}(t)=f\left(\int_{t o}^{t} s_{i} P_{i} d t\right) .
$$

The ISODE package performs all control of numerical error in the solution, under the condition that the error per solver step in $p_{1}, \Delta P_{i}$ is

$$
\Delta P_{1} \leq 2 \times 10^{-10}+\left(1 \times 10^{-4}\right) P_{i} .
$$

This provides both absolute $\left(1=10^{-10}\right)$ and relative $\left[\left(1 \times 10^{-4}\right) P_{i}\right]$ error control, and in testing it has maintained at least three significant figures of accuracy in the output. It should be noted, however, that in problems having pressures on the order of $10^{-7}$, results may be inaccurate. These parameters can be adjusted by changes in subroutine BAG, but it must be noted that such changes will influence the tlme reguired for solution.

\section{AVAI LABILITY}

The executable code DYNAVAC, the source file DYNAVACs, and the input file for the sample problem in this report, DYNAVIN, are available by ruming FILEN as follows:

FILDS $/ t y$

RDS . 3042 . VACUUM DYNAVAC DYNAVACS DYNAVIN Before running the sample problem, the file name must be changed to Vacin, which can be done with utility routine switch SWITCH DFNAVIN VACIN $/ t v$.

\section{EXECUTION}

DrNaVAC is eun by simply executing the controllee DYNAVAC, and suppiying an input file named VACIN. DYaAVAC outputs several lines of information to the terminal, concerning the code itself and the problem it is solving. It generates four different files which are left on disk. The printed output for the problem is in file VACPRT, along with an echo of the input information. The plotted output is ieft on disk with a file name of the form Fx105/ hhmm, where the last four aigits (hhmm) are the time the file was generated. The 
two cemaining files should be of little interest to the user. File sCratcH contains the pressure yg time output data; this file could be used as input for other codes for various purposes. File VACERR contains information concerning the actual solution of the equations, including any messages sent by the solver ISODE. If DYNAVAC terminates during the solution of the equations, this information can be useful in determining the cause.

INPUT

All input to DYNAVAC is in the file VACIN, which must be present for DYNAVAC to execute successfully. If VACIN cannot be found, execution will be terminated by ORDERLIB ERROR 28*. All input is formatted as shown in square brackets below. Integer data must be right-justified and must not include a decimal. All other numerical data should be entered with a decimal point, unless the default input format (generaliy E10.3) is used; use of a decimal point will override the default format. If non-imbedded blanks are encountered, they are read as zeros. Numerical limits are indicated in parentheses below.

$$
\text { File VACIN is constructed as follows: }
$$

A. TITLE CARD $[10 \mathrm{A4}]$

$\operatorname{col} 2-40$ TITLE

- up to 40 characters which will be output at the top of each page of

B. MASTER CONTROL CAFD [4I5] output

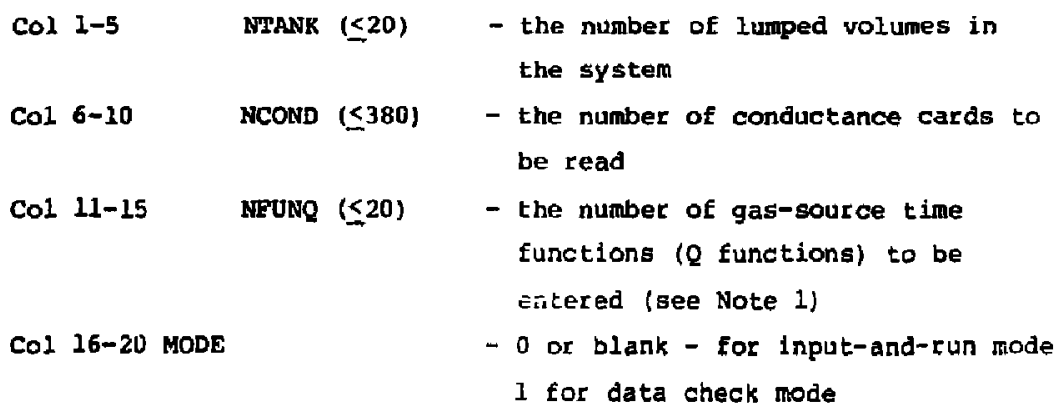

c. VOLTME CAROS - HTANK sets of cards requiced

1) VOLUME TITLE CARD $[10 \mathrm{~A} 4]$ 
Col 1-4C VTITLE

2) VOLUNE DATA CARD $[4 E 10.3,215]$

$\begin{array}{ll}\text { Col 1-10 } & \text { vOL }(\geq 0.0) \\ \text { Col } 11-20 & \text { SPD }(\geq 0.0) \\ \text { Col } 21-30 & \text { Q }(\geq 0.0) \\ \text { Col } 31-40 & \text { P }(\geq 0.0) \\ \text { Col } 41-45 & \text { NPTS }(\leq 20)\end{array}$

Col 46-50 ITUNo
- up to 40 characters to be output in the heading for the graph for the volume

- the volume

- the pumping speed (ignored if a speed table is used)

- the gas source rate

- the inftial pressure

- the number of points in the speed table (0 or blank for constant pumping speed)

- the number of the $Q$ function for this volume $(0$ or blank for constant gas gource rate - see Note 1)

3) SPEED TABLE CARDS [2E10.3] - NPTS cards required (see Note 2)

CoI $1-10$ QINT $(\geq 0.0) \quad$ - total integrated gas pumped

Col 12-20 SPD $(20.0) \quad$ - the pumping speed at QINT

D. CONDUCTANCE CARDS $[215, E 10.3]$ - NCOND cards required

$\operatorname{col} 1-5 \quad I$

Col 5-10 J

Col 11-20 $C(I, J)(\geq 0.0)$ - The conductance from volume I to volume J. By default $C(J, I)=$ $C(I, J)$ unless both are input. If neither is input, the default is zero.

B. Q FUNCTION CARDS - MENQ sets of cards required

1) Q FUNCTION CONTROL CARD [I5]

Col 1-5 NPTQ $\leq \leq 20)$

- the number of points in the $Q$ flinction table

2) Q FUNCTION TABLE CARDS [2E10.3] - NPTO cards required
$\cos 1-10 \quad T$
Col $11-20$ FU $(\geq 0.0)$

- time
- the $Q$ function value at time $T$ (see Note 1) 
F. PROBLEY CONTROL CARDS - one and only one set reguirid (bee Note 3)

1) TINE BLOCK CONTROL CARD $[$ I5, Elo.3]

Col 1-5 SBLock ( $\leq 10)$ - the number of blocks of equally spaced time steps

Col 6-15 To - the initial time

2) TIME BLOCK CARDS [I5, B20.3] - NBLOCK "ards required

$\begin{array}{lll}\text { Col 1-5 NSTEP } & \text { - the number of time steps in the } \\ & \text { block } \\ \text { Col 6-10 TSTEP } & \text { - the length of the time step }\end{array}$

NOTES

1) Time-dependent gas-source rates are handled in the followiag manner if IFUNQ is greater than zero for a volume. (If IFUNQ is tero for a voluse, the gas source is not time-dependent.) The gas source rate at any time is given by $Q^{*} F Q$, where $F Q$, the $Q$ function value, carried the time dependency. $F Q$ is determined for a particular volume at a particular time by going to the $Q$ function table for that volume and linearly interpolating between points. The first and last points of any table are extrapolated as constant values. Any number of volumes can use the same $Q$ function, if it is desired to give them all the same time dependence.

2) Fumping speeds can be a function of the total integrated gas pumped in a volume, if NPTS is greater than zero. (If NPIS is equal to zero the pumping speed is constant.) The total integrated gas pumped in $a$ volume is obtained by doing the stepwise integration

$$
\mathrm{QINT}=\sum \mathrm{Pi} \text { si } \Delta t
$$

where $P f$ is the average pressure during the time step $\Delta t$ in volume $i$. The pumping speed is then given as a function of QINT. The pumplng speed at any time is determined by going to the volume's speed table with the current value of QINT, and linearly interpolating between points. The first and last points are extrapolated as constant values. If a speed table is used, SPD on the volume data card is ignored.

3) There mist be less than a total of 1000 time steps per problem. 
4) Ary units can be used, rat they must make a consistent set; that is, they must fit in the system equation correctly. A useful oet is as follows: pressure in Torr, volume in liters, time in seconds, conductarces and pumping speeds in liters per second, gas source rates in Torr-2iters per second, integrated gas pumped in Torr-11ters, anj $Q$ function unitless.

OUTPUT

Tip

When DYnAVAC is executed, three lines are normally sent to the user"s ITY. The first line is information on the DYNAVAC version that is curcently being used; it consists of eight integers separated by decimal points, each lateger referring to the version number of one of the eight main DYNAVAC subroutines. If trouble is encountered in running a version of DYNavac just retrieved from public storage, check these numbers to see if changes have bagn made in the code 1tself. A further aid in this situation is the compilation date, also output at the TTY. Normally, the final line of output is the title line from the problem DYNAVAC is currently worklng on. However, if errors are encountered during execution, additional information will be output to the ITY, depending on the circumstances. If an error is found in the input data, it is printed on the HY, and the rest of the input file is checked, regardless of how many errors are found.

\section{Printed}

File VACPRT contains the printed output from the problem. It consists of a Eormatted eche of the input file, followed by the pressure vs time dita. If errors are encountered in the input, the entire input file is still checked, and information on errors is printed in VACPRT.

File VACER contains information useful in the event of probiems in the solution. For each output time step, VACERR contains the total number of steps taken internaliy by LSODE, the total number of evaluations of the system equations and the system Jacobian, and the last internal time step used suacesefully by LSODE. In addition, VACERR contains any messages sent by ISODE.

File SCRATCH contains only the pressure vs time data. This data may be useful as input for post-processing codes, bL: usually the file can be ignored. 


\section{Graphical}

DYNAVAC produces FR80-format plotfiles with names of the form FX105/hhmm, where hhum is the time the file was generated. These files can be output using NETPLOT with the F. soption. If the L. op'ion is also used, the plots will be of an appropriate size for an $81 / 2 \times 11$ page.

DYNVAC produces two types of graphs. The first set of graphs consists of the pressure vs time data for all volumes plotted to the same scalc. In this set there are five plots per graph on as many graphs as are req..1red. Following these plots are individual plots for each volume, each to an appropriate scale for that plot. The second set allows one to examine in detail the response of each volume on the individual plots and compare it to all volumes on the combined graphs.

The following example demonstrates many of tie features of Dywavac. A schematic of the system model is shown in Fig. 1. This groblem invol.ves a TMx-like geometry, including all leakage paths from volume to volume as conductances. There are three gas sourcos: a gas box in the plug area, and neutral beams in the plug and center cell. In this example, the neutral beams operate simultaneously and the gas box comes on 0.005 seconds af ter them. Note thet this is acromplished by using only two $Q$ functions: the first for the gas box and the second for both reutral-beam clusters. Alsc note that although the $Q$ function is the same for yolumes 1 and 9 , the actual gas loads are different (corresponding to 10 sources in the plug and 4 sources in the central cell) by means of the $Q$ values entered on the volume data cards. For both the neutral beams and the gas box, the fas source is assumed to turn on instantly, remain on at a constant rate, and then ramp down to zero in 0.005 seconds (see Fig. 2).

In volumes 2,3 , and 5 , the effect of saturation of surface pumping was modelled by using variable purping speeds. It is assumed in all three cases that the pumping speed initially decreases linearly with gINT (the total gas pumped in the volume), and then levels off at a constant value (see Fig. 3). This can be entered with only two points in the speed table, since DYNAVAC interpolates between points, and extrapolat a constant value from the first and last points.

The time control is set up to output from time zeto to 0.1 in steps of .001 , from 0.1 to 0.3 in steps of .005 , and from .3 to .5 in steps of .01 . 


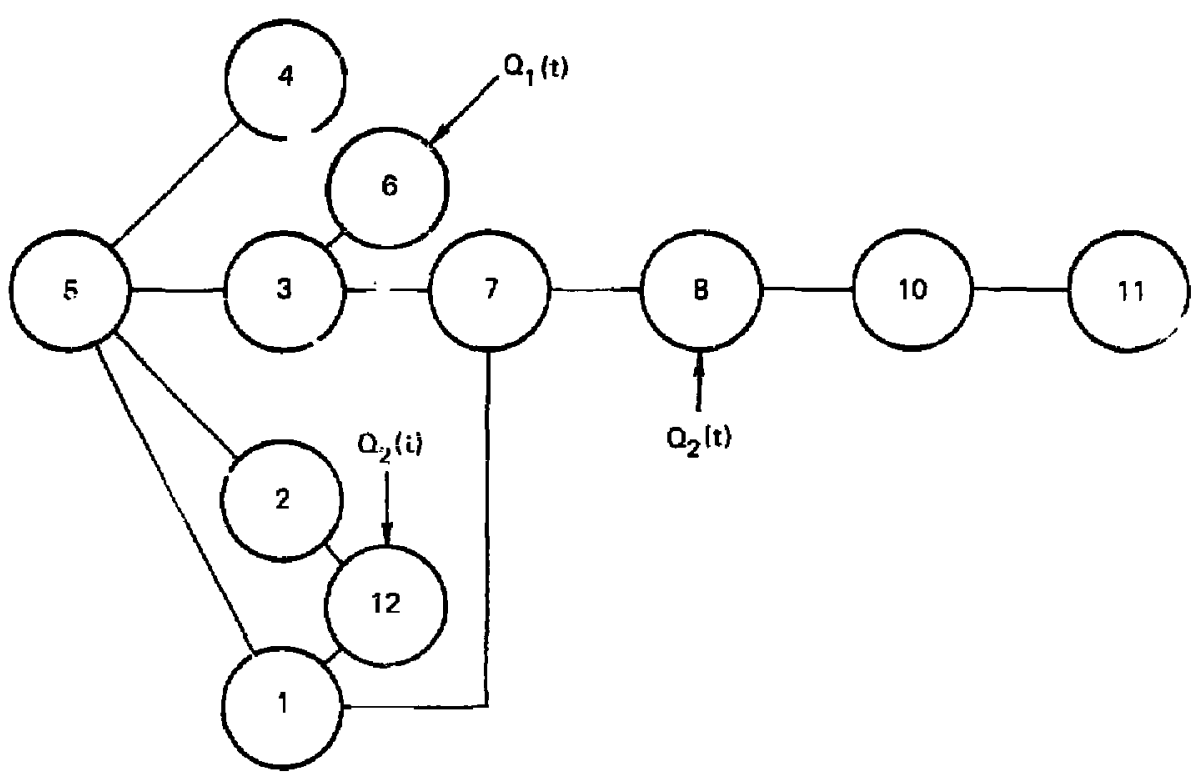

FIG. 1. Schematic of syster model for Example problem.

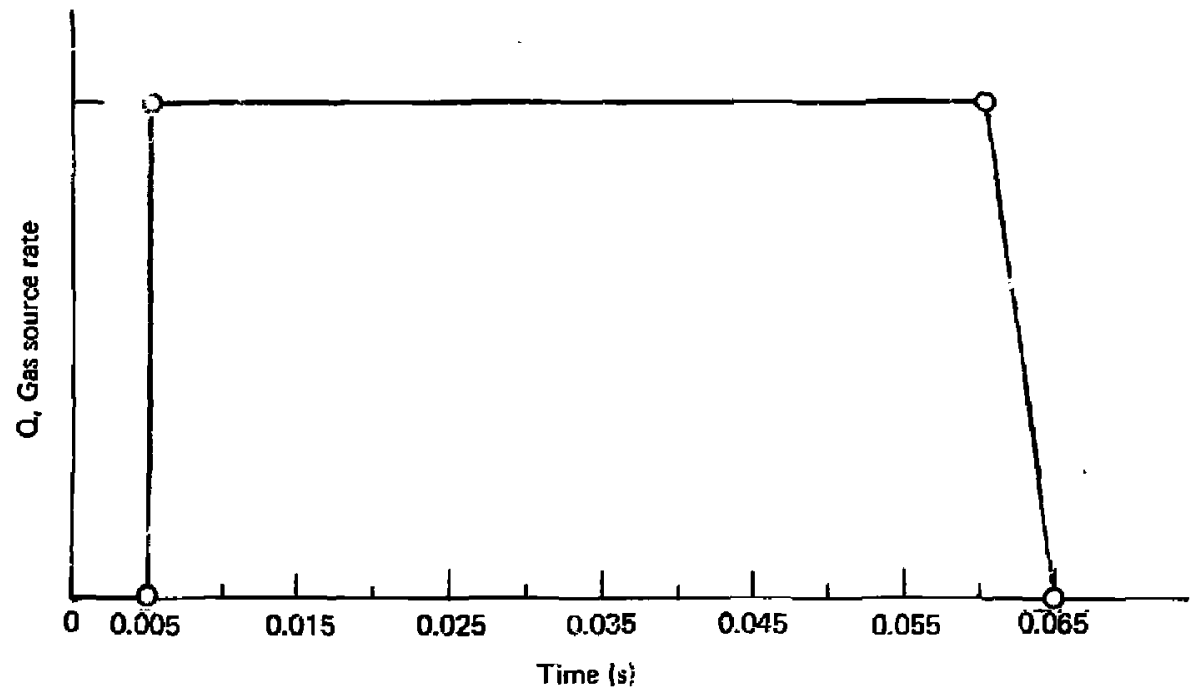

FIG, 2. Variation of gas-source rate for volume 6 with time. Circles denote input peints. 


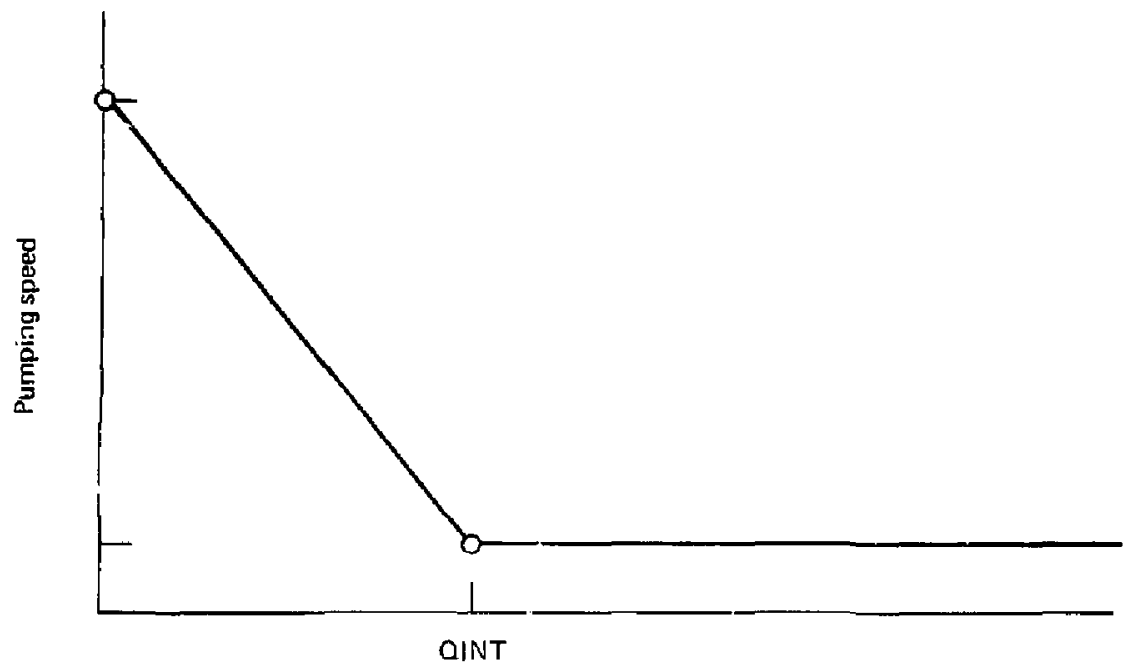

FIG. 3. Pumping speed characteristic for volumes 2,3 , arı 5. Circies denote input points.

11

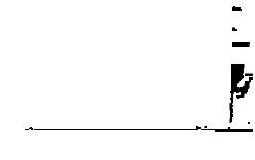


The units used in this example are Torr, 1iter, and seconds.

The input file, vacin, for this example is show in Fig. 4. Printed output from file VACPRT is shown in Fig. 5 , a-c, with only one page of data included. The entire set of graphs produced for this problem is shown in Fig. 6, a-n. Finally, one page of printed output from file VACERR is shown in Fig. 7 . 


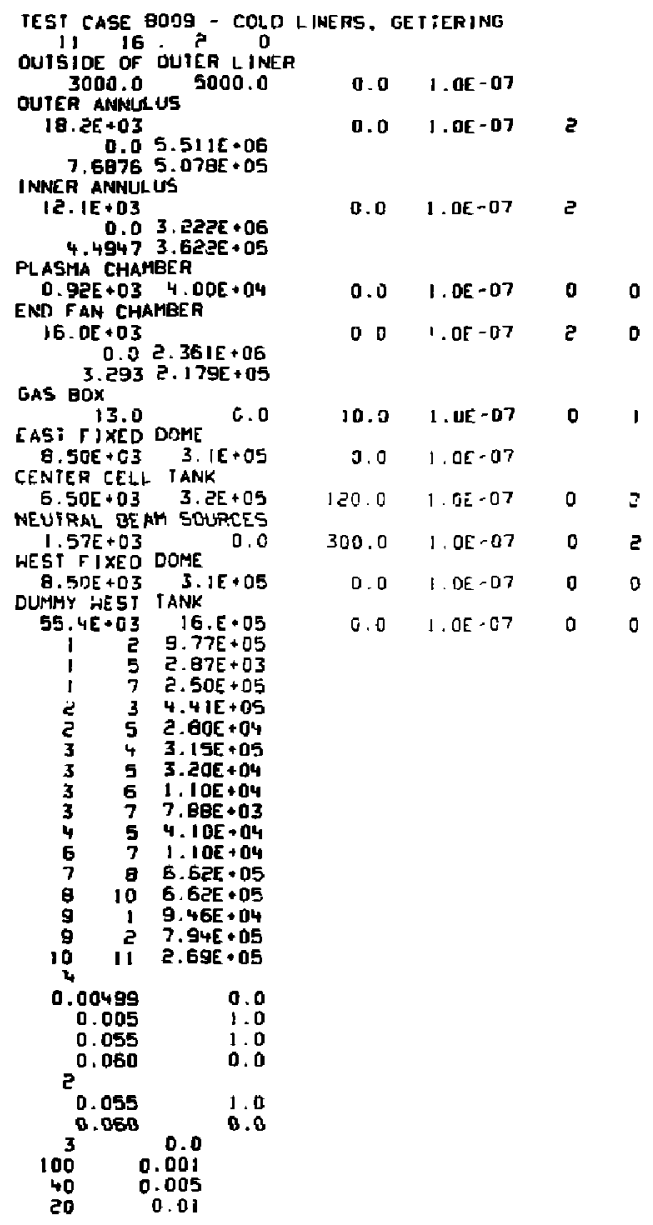

FIG. 4. Input file (hCIN) for example problem. 
TEST CA5E gDOS - COLD LINERS. GETTERING

NUMBER OF VOLUMT.S

\section{$=11$}

NUMBER OF CONCUC TANCES $=16$
NUMBER OF O TUNCTIONS $=?$

VOLUME I - DUTSIDE OF OUIER LINER VOLUME $=3.000 \mathrm{D}+03$ [N] I IAL PRESSURT. $=1.000 E-07$ $\begin{array}{ll}\text { GAS SOURCE } & =0 . \\ \text { PUIMPING SPEED } & =5.000 E+03\end{array}$

VOLUME 2 - LUTER ANNULUS

VOLUME

INIIIIAL PRESSURE $=1.000 E-07$

PUMPINE SPEE TABLE, a POINIS,

INTIS.P-DT: SPEED

0. $5.511 \mathrm{~T}+05$

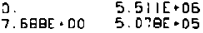

VRLUME 3 - INNER ANIJULUS

VOL UHE
INIIIAL PRESSURE $=1.210 E * 04$
GAS SOUACE

GAS SOUACE PUMPING SPEE IABLE, I POINTS

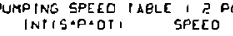

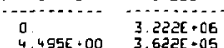

Vol U:AE 4 - Plasma chamaER

YOLURE PLASML CAATER $=9.2000+03$

INITIAL PAESSUAE $=1,000 E-07$

CAS SOUFEE $=$ SUMP ING SPEED $=400 E \cdot 04$

YOLUME 5 - END FAN CHAMBE $R$

VOLUME
INITIAL PAESSURE $=1.600 E \cdot 04$
GOS SOURCE

GAS SOUACE PUTPING SPCEO TAGLE, 2 POINISI

INIIS.P.OT, SOEEO

$\begin{array}{ll}\text { 0. } & \text { 2. } 351 E \cdot 06 \\ 3.293 \cdot 00 \quad \text { 2. } 179 E \cdot 05\end{array}$
VOLLMF 6 - GAE BOX

VOL UME
IAI TIAL PAE SSURE $=1,300 E+01$
GAS SDURCE
$1.000 E-07$ GAS SDURCE $\rightarrow 1.000 E-0$ O FUNE $110 \mathrm{~N}$ Pumping saked $>0$

YOLUME 7 - EAST FIXED DOME

VOL UME EAST FIXED $=8.500 E+03$ GAS SOURCE - 0 . PUMPING SPEED $\quad 3.100 E \cdot 05$

VOLUME $B$ - CENTER CELL IANK VOtUME INIIIAL PRESSUAE $:$, OOOE-0 GAS SOURCE $\begin{array}{ll}\text { D FUNCTION } & =3.200 E \cdot 05 \\ \text { PUMPING SPEED } & =3.200 E\end{array}$

VOLUME $Y$ - H.,1FAL BLAH SOURCES VOL URE CAS SOUACE SLAE = $3.0002-07$ FUNCTION

PUMPING SPEEO =

VOLUME 10 - HeST FIXED DOME VOLUME GAS SRITCE: SSUAT: $1.000 E-07$ piztir ING SPECO - 3.100E.05

WILUME II - OUMAT WEST TANK YOLUME IN! TIAL PRESSURF I 1.000E-0 GAS SOUFCE
PUMPING SPEEC $\begin{aligned} & =1.000 E-07 \\ & =1.600 E+06\end{aligned}$

(a)

F1G. 5. Printed output (VACPaT) for exampie problen. 


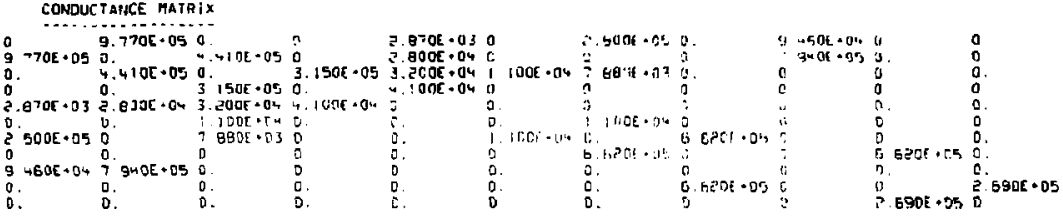

D fUnCTION NUHEER I. i L DOINTS

i IME

$4.9905-03$

$1.0005=00$

.

6. $0005-02$ a

a.

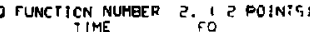

$\begin{array}{ll}5.500 E-02 & 1.000 E+00 \\ \text { 5.000E-0E } & 0.00\end{array}$

PROELEM CONTRNL

MUMBEA OF TIME GLOCKS : 3

INITIAL TIME NSTEP TSIL

$\begin{array}{lccc}\text { ELOCK } & 1 & 100 & 1.0005-03 \\ \text { ELOCK } & z & 40 & 5.0008=03 \\ \text { BLOCK } & 3 & 20 & 1.0005-02\end{array}$

(b)

FIG. 5. (Continued) 
IOVNaVAC- TEST CA5E gOOg - COLO LINERS, GCTrERINO

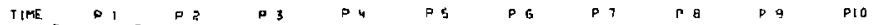

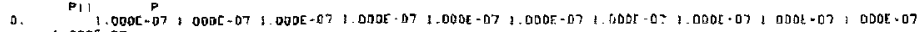

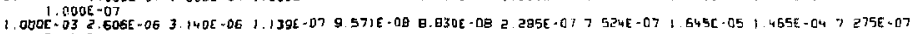

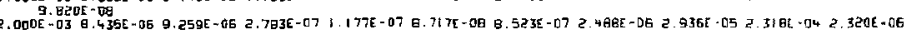

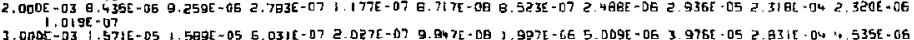

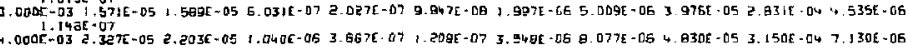

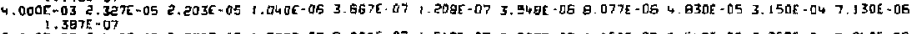

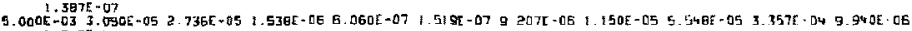

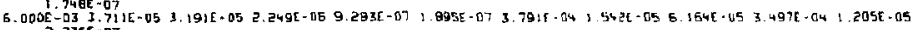

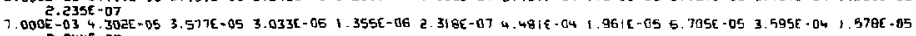

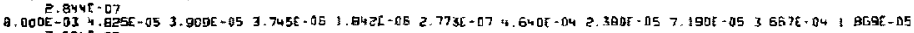

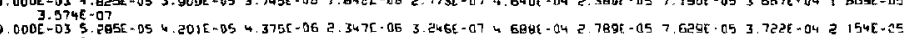

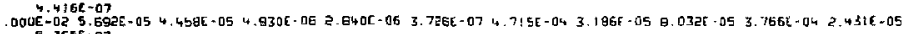

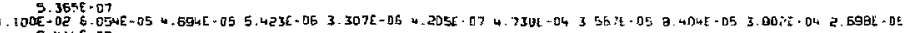

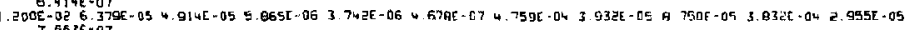

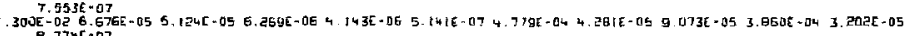

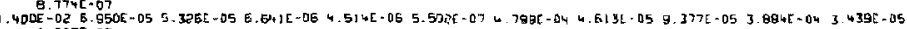

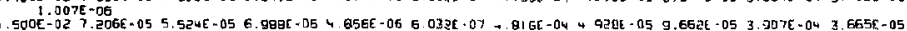

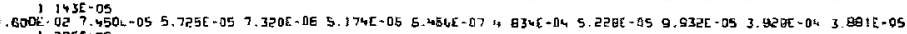

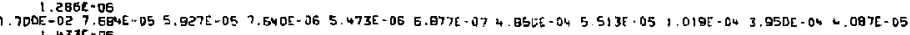

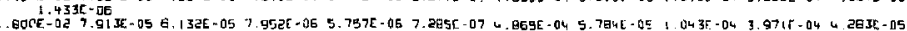

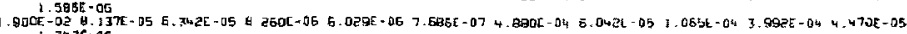

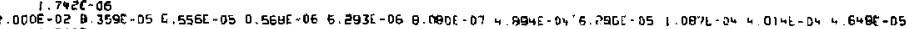

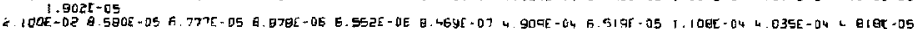

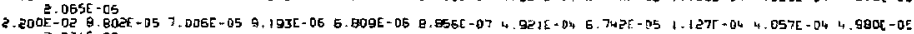

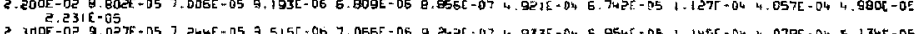

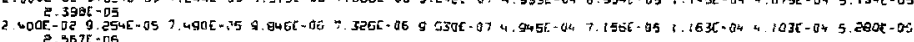

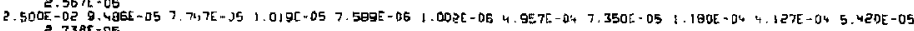

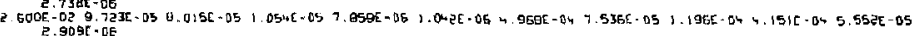

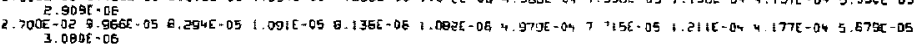

EIG. 5. (Continued) 


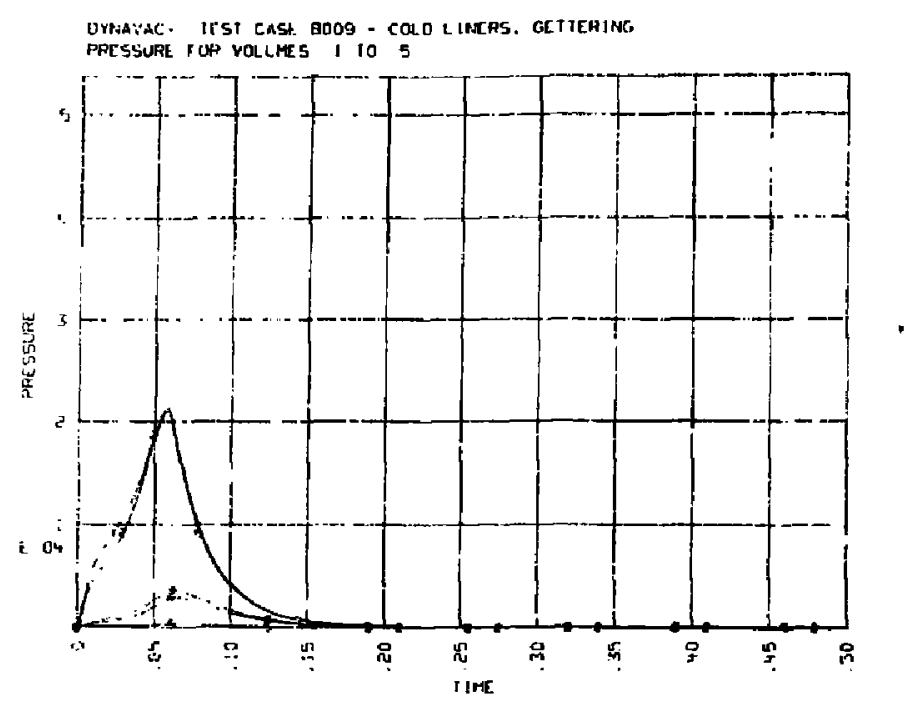

(a)

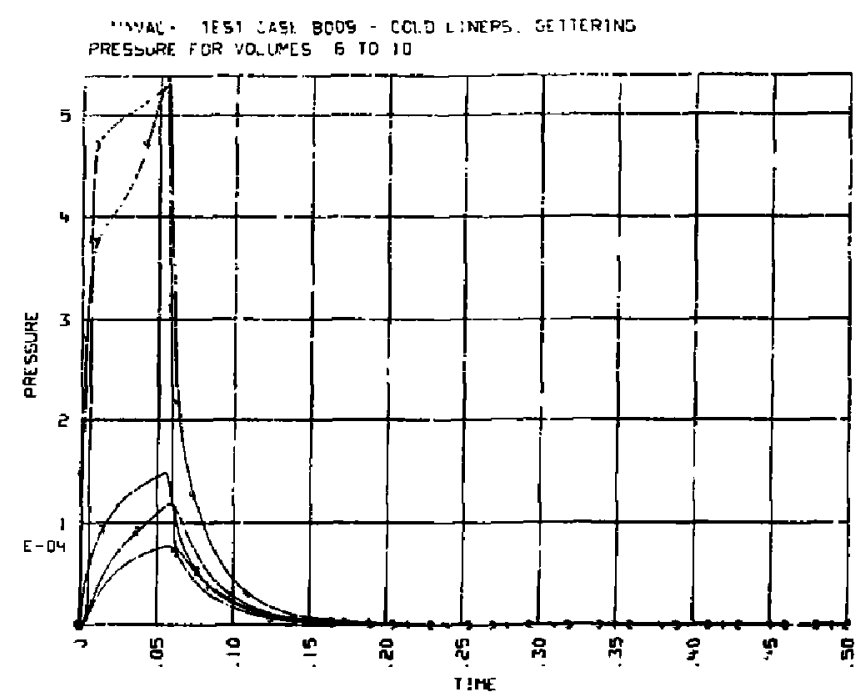

(b)

FIG. 6. Graphical output for example probler . 


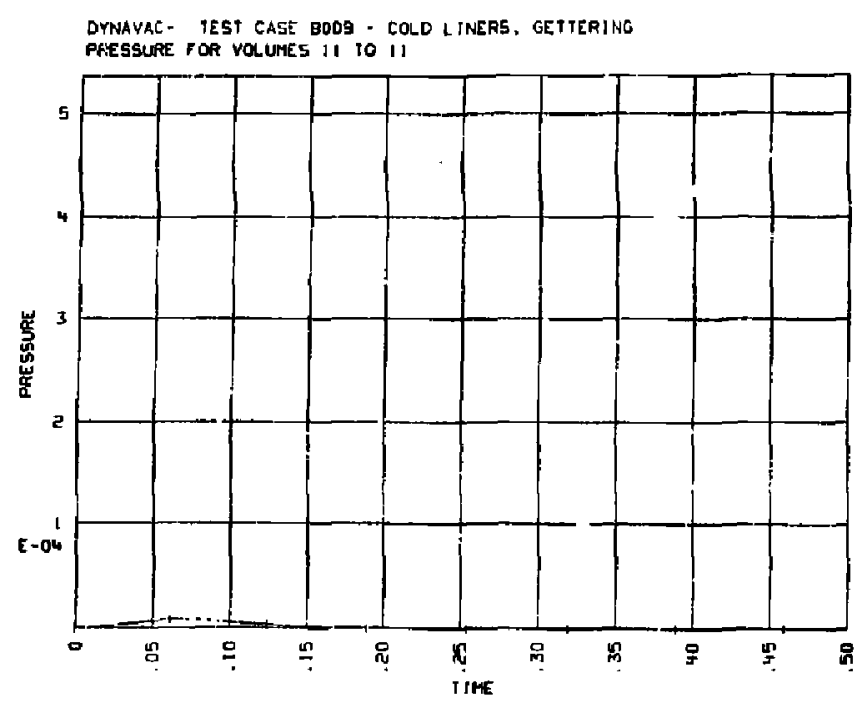

(c)

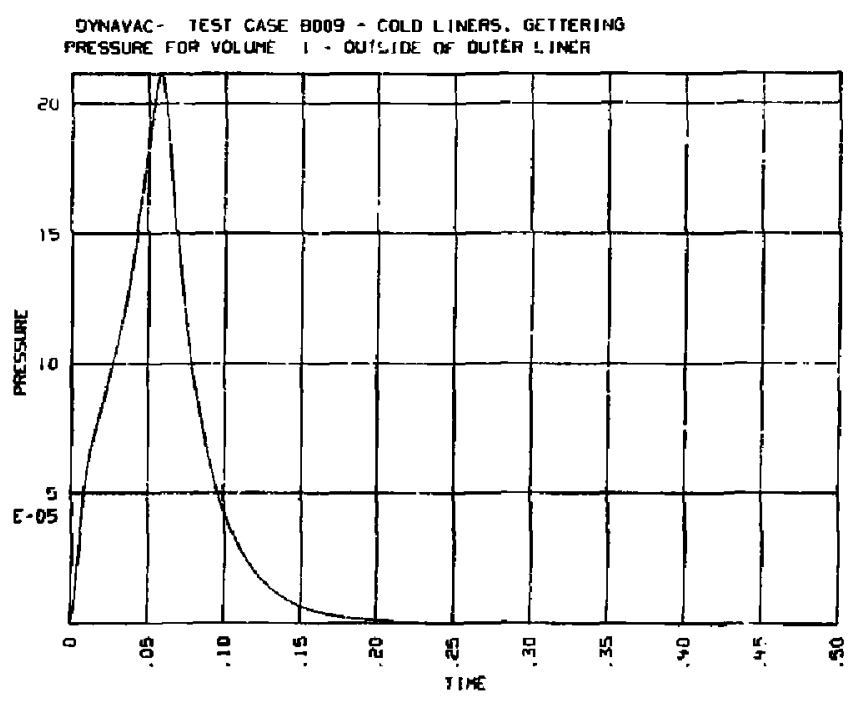

(d)

FIG. 6. (Continued) 


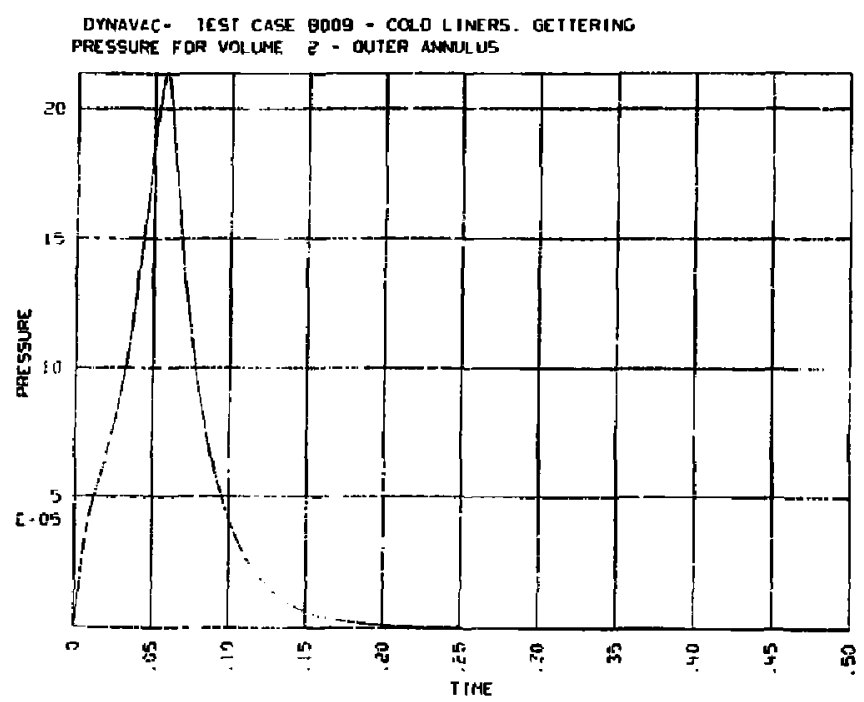

(e)

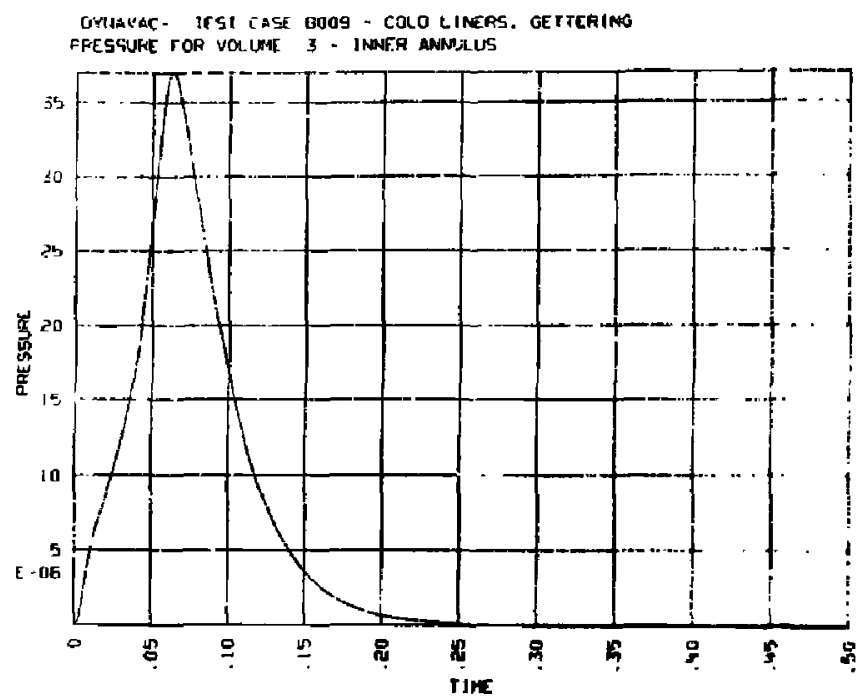

(f)

FIG. U. (Continued) 


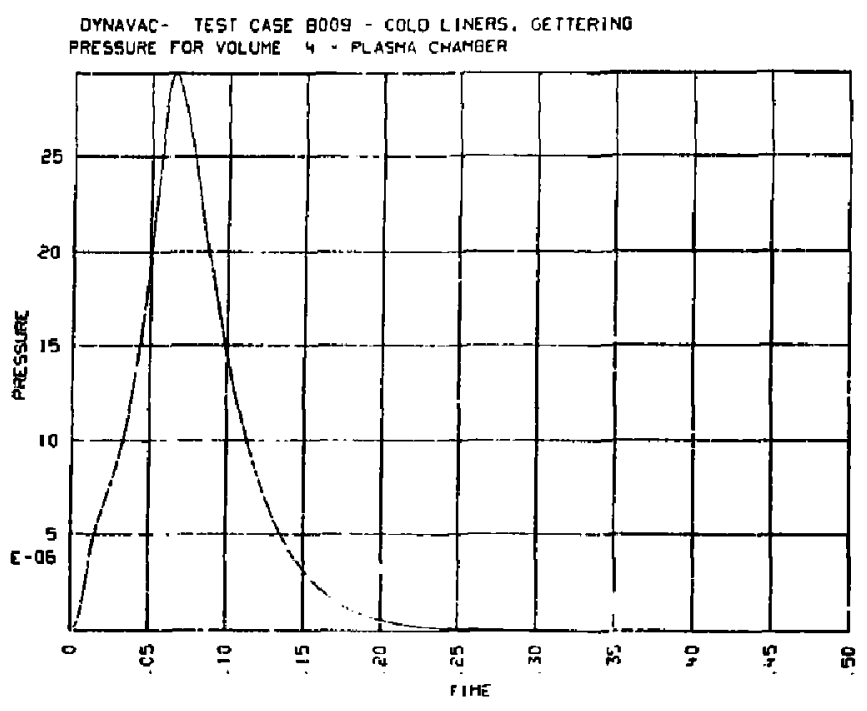

(g)

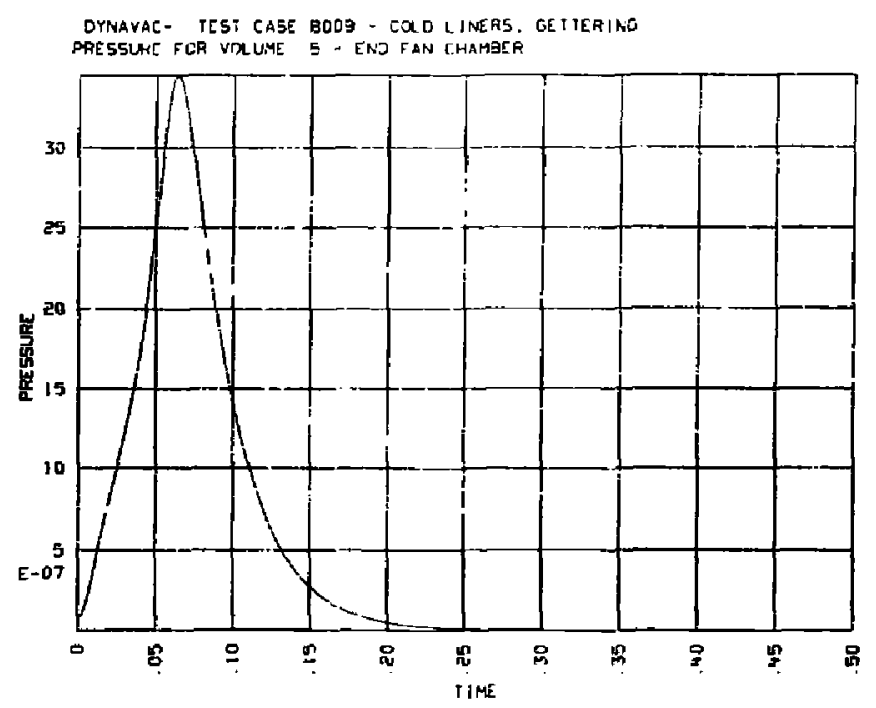

(h)

FIG. 6. (Continued) 


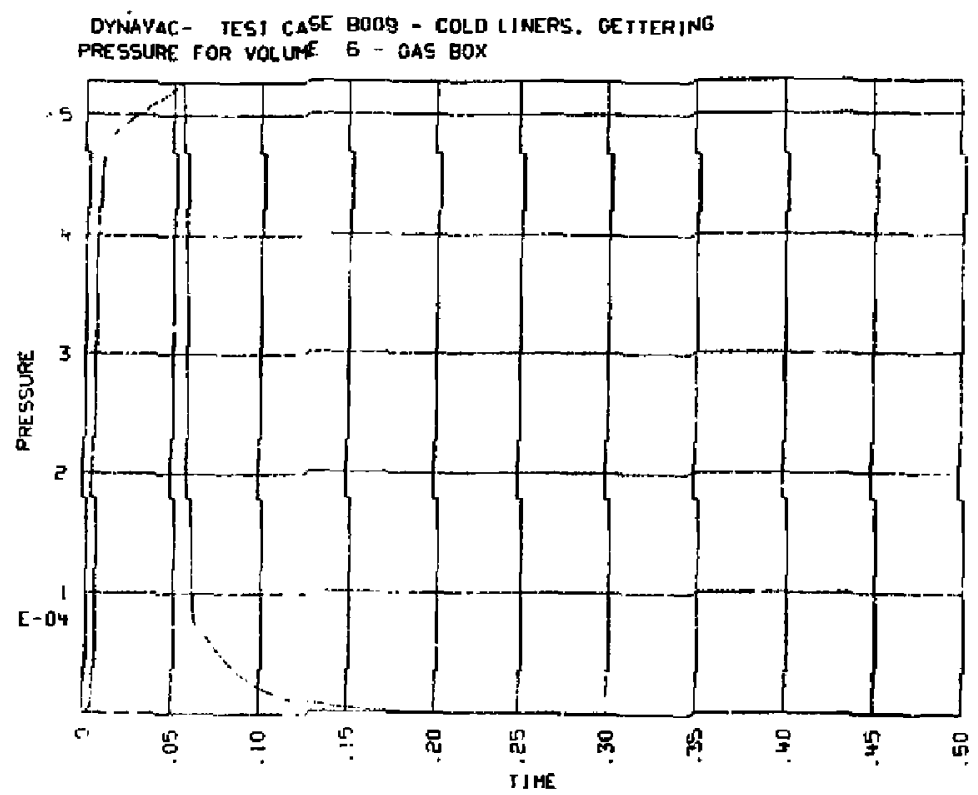

(i)

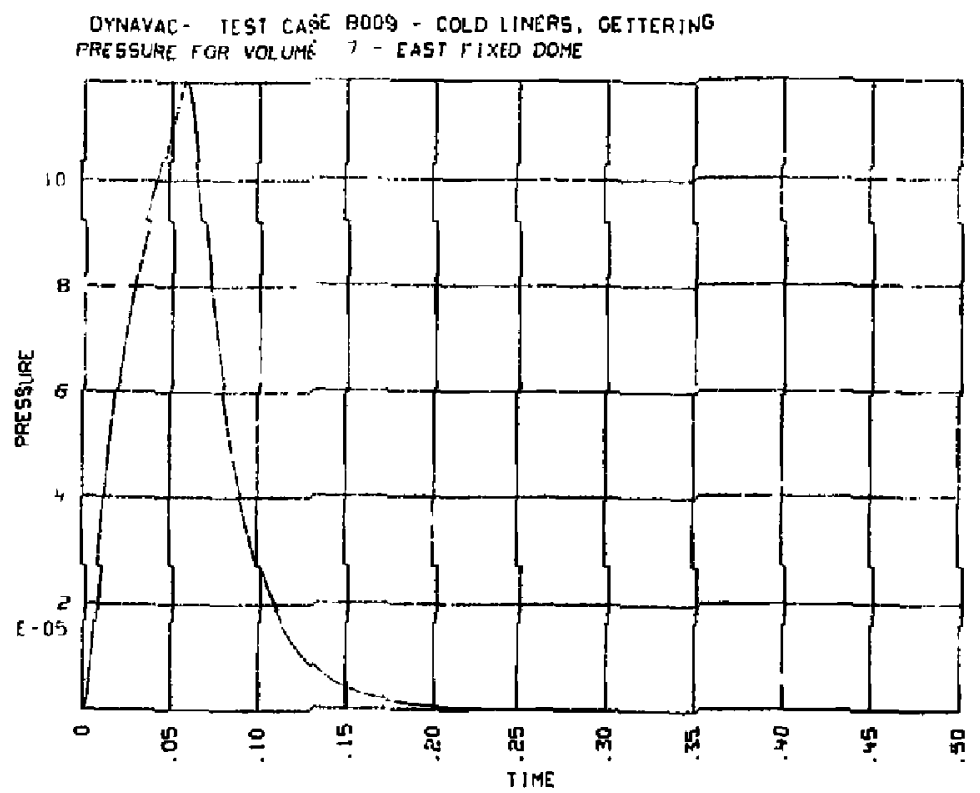

(j)

FIG. 6. (continued) 


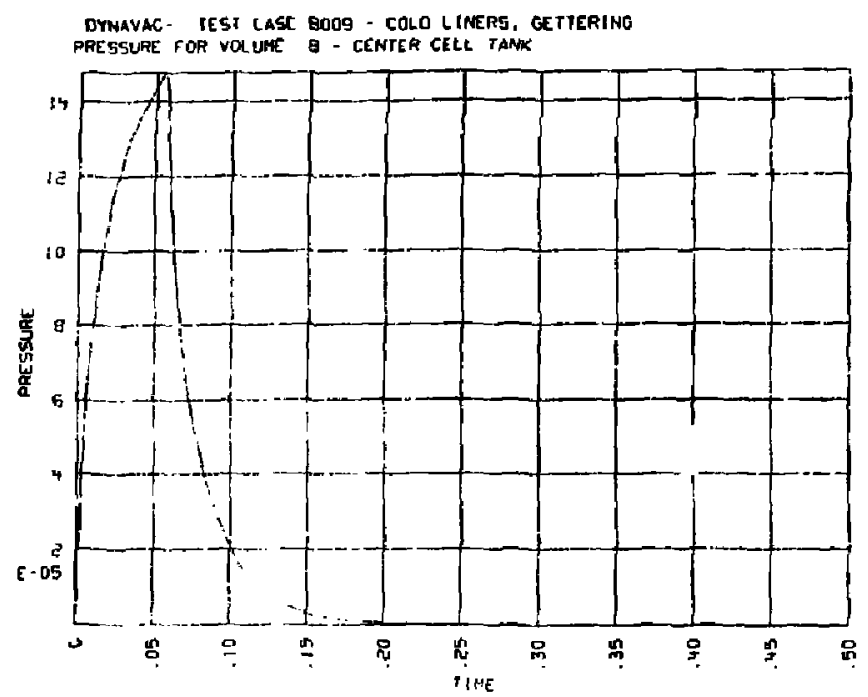

(k)

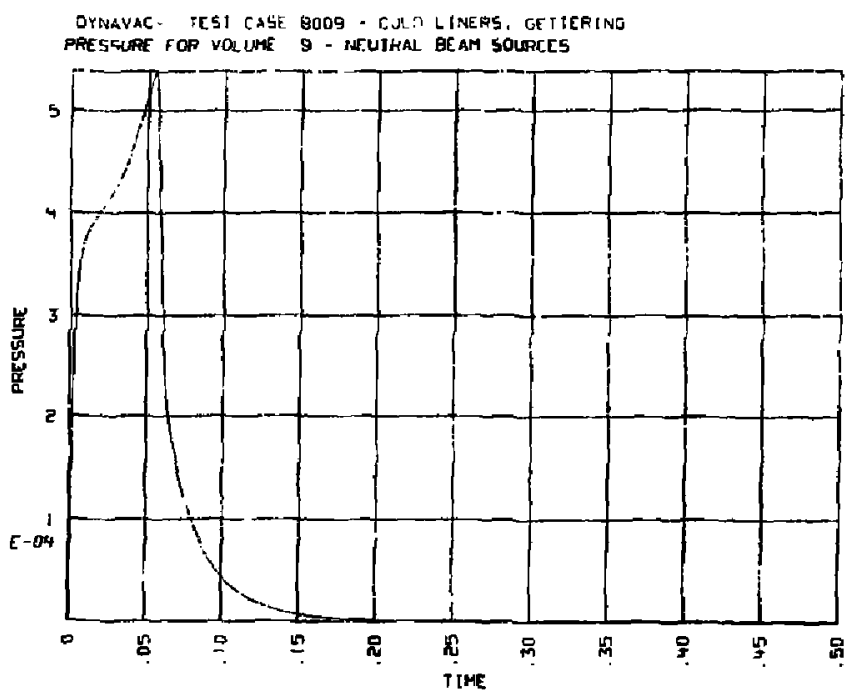

(1)

FIE. 6. (Continued) 
OYNAUAC - TEST CA5E BOOS - COLD LINEAS, GETTERINQ

FRESSURE FOR VOLUME 10 - WEST FIXED DOME

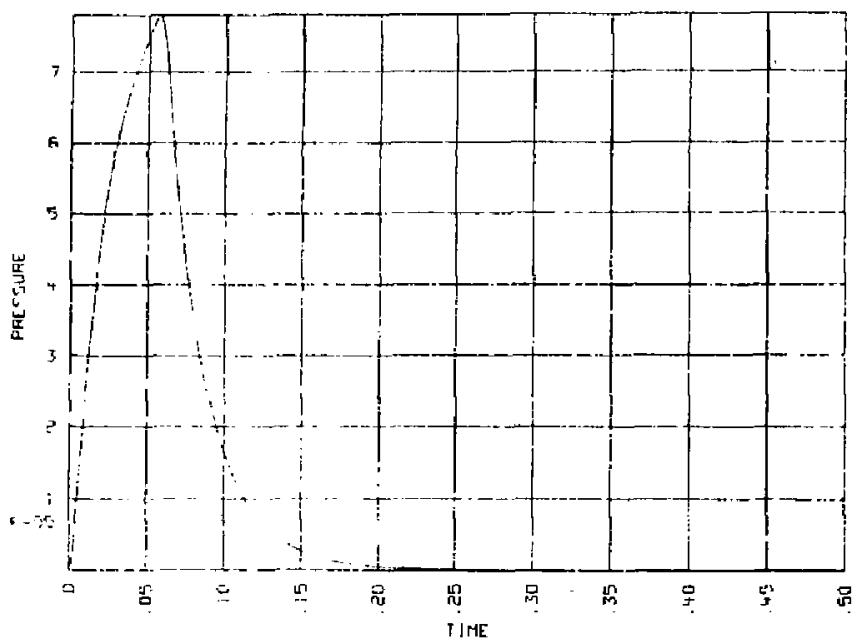

(m)

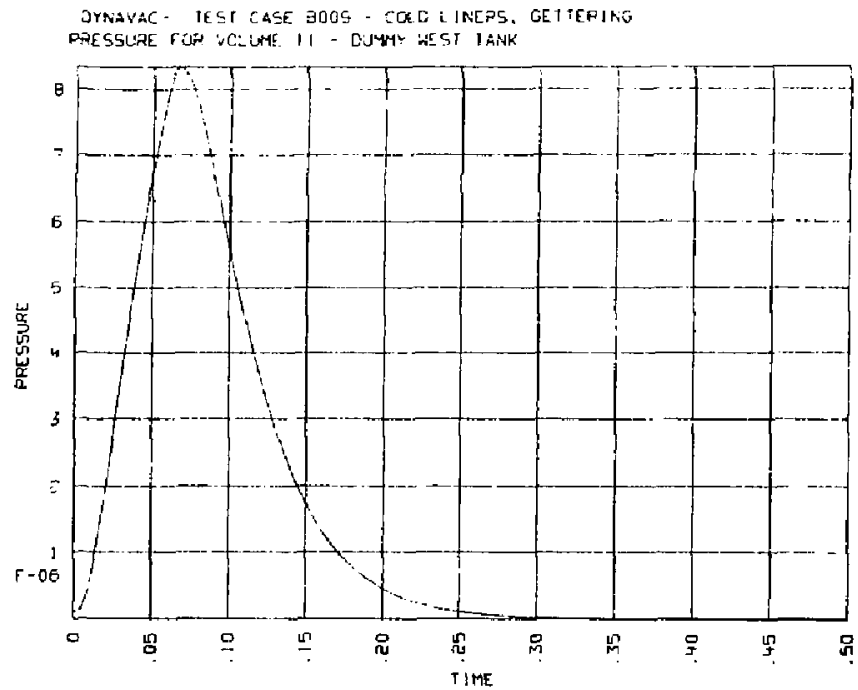

(n)

FIG. 6. (Continued) 
THIS IS FILE VACERF

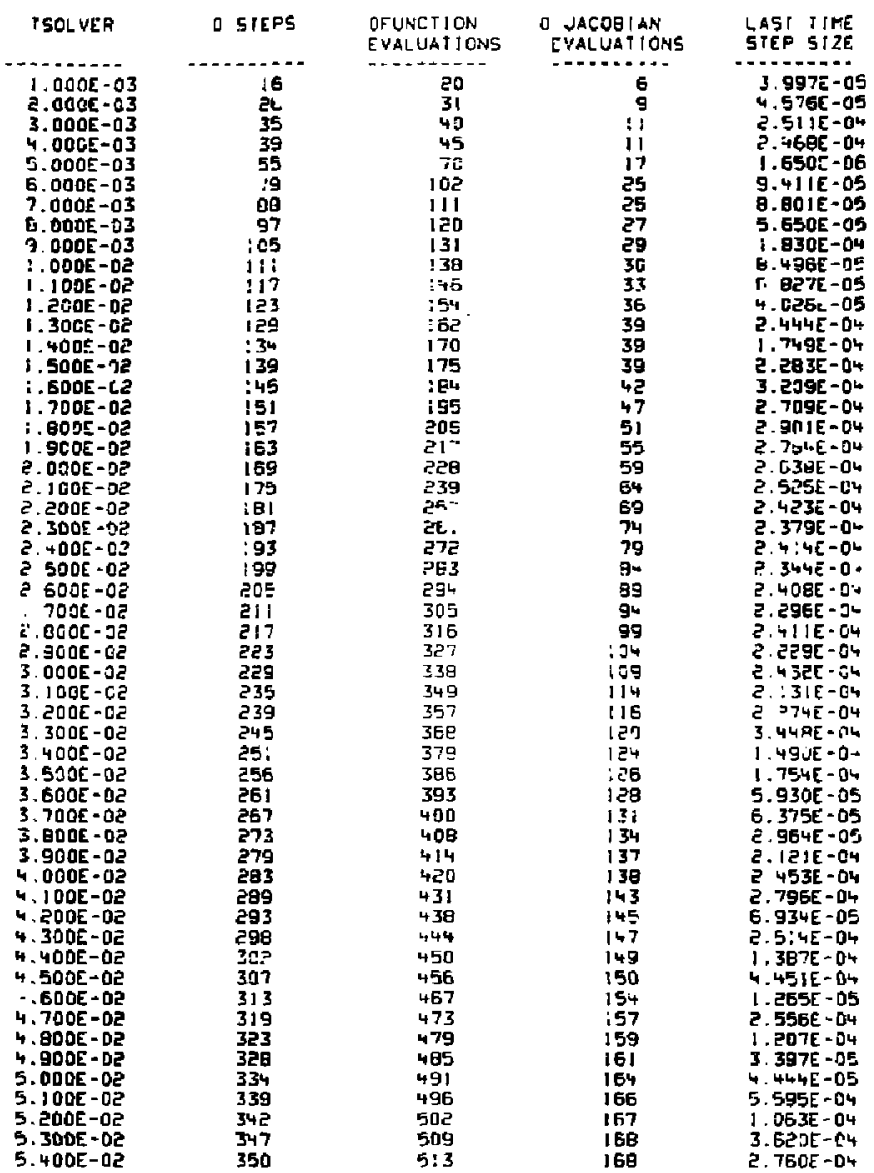

FIG. 7 Printed cutput (VACERR) for example problem. 
DYNAvAC has been written in a modular fashion to facilitata modifications and additional capabilities, and the following discussion of its structure will be of interest to users who intend to make such changes.

DYNAVAC consists of a short main fiogram, 7 other DrwAvac subroutines, and the I3OnE package which consists of 21 subroutines in all. The main program, DYĩAVAC, serves mainly as a calling routine, witb some minor problem control responsitilitier. It first calls subroutine nOSE, which handles all input, error check $1 \pi y$ of input, and the echoing of the input data. 111. data is passed to other subroutines via COMON's. When HOSE returns control. to DYMAVAC, subroutine BAG is called. This subroutine actually nbtains the solution at the desired autput times by refealed calls to LSODE. In addition, BAG checks fot indlcailows of trouble from LSODE, and performs a stepwise integration to calculate GTNT for each volu re. The pressure vs time output data is written into fil: SCRATCE in a form suitable for later use. then the sclution is complete, control is returned to Druva:. The next subroutine called is EXHAUST, which handles all cf the output functions, It reads all of the output data from file SCRATCH, and then produces all of the printed and plotted output. Control is then returned to DVNAVAC, which terminates the run. If at any point an error occurs which has been anticipated in the coding (such as a negative volume input, or problems with LSODE), control is transferred at an appropriste time from whatever subroutine is executing, through DYNAvac to subroutine PLuG. Currently, this subroutine just prints a brief message with suggestions to help in fixing the problem, and then terminates the run grace.Eully.

These flve routines determine the main flow of operation of DYtiAVAC. There are, however, three routines supplied besides LSODE and its subroutines. These three routines are called by ISODE to provide information needed for the solution. The first of these, PDERIV, is basically an explicit coding of the system equations. It merely loads array PDOT by using array $P$, the time T. and the system properties. This subroutine also performs the determination of the gas-source rates, by interpolation or extrapolation of the appropriate $Q$ function. Subroutine PDERIV also calls subroutine cosDuCTANCE. which loads all of the system $r$ : pperties Into the array $c$. This simplifies the coing in 
POERIV. CONDOCTANCE actually determines the pumping speeds (where they are variable) by using QRNT, as calculated in BAG. The final DYNAVAc subroutine which may be of interest is subroutine PJAC, which supplies the system Jacobian matrix, PD, defined as

$$
\text { PF }(I, J)=\frac{\partial}{\partial P(J)}\left(\frac{\partial P(J)}{\partial t}\right) \text {. }
$$

This matrix is equal to the $\mathrm{C}$ matrix (from subrouthe CoNbucrakce) divided by the volumes. It is nci necessary for PJAC to call CONDUCTAtre, since PJin is never called unless PDERIV is called first.

The or.ly other subroutines used are those in the LSODE package, and a detailed dicussion of these routines will not be attempted here. Reference 3 shrusd be consulted for such a discussion, if uSODE modifications are contemplated. For a discussion of the general user interface requirements for LSODE, see the comment lines below line 651 in the source listing, DYMaVacs. In the following pages, the source listing for ISODE and its subroutines has been omitte. , leaving only the eight DYNAVAC subroutines. In DYaAvacs, the ISODE package beyins helor? line 651. 
PROGRAM DYNAVAC IVACIN, TAPE $7=V A C$ IN, VACPRT, TAPE5=VACFRT, ISCRATCH , TAPE 9=5CRATCH, VACERR. TAPE 3 = VACERR , TAPES9 )

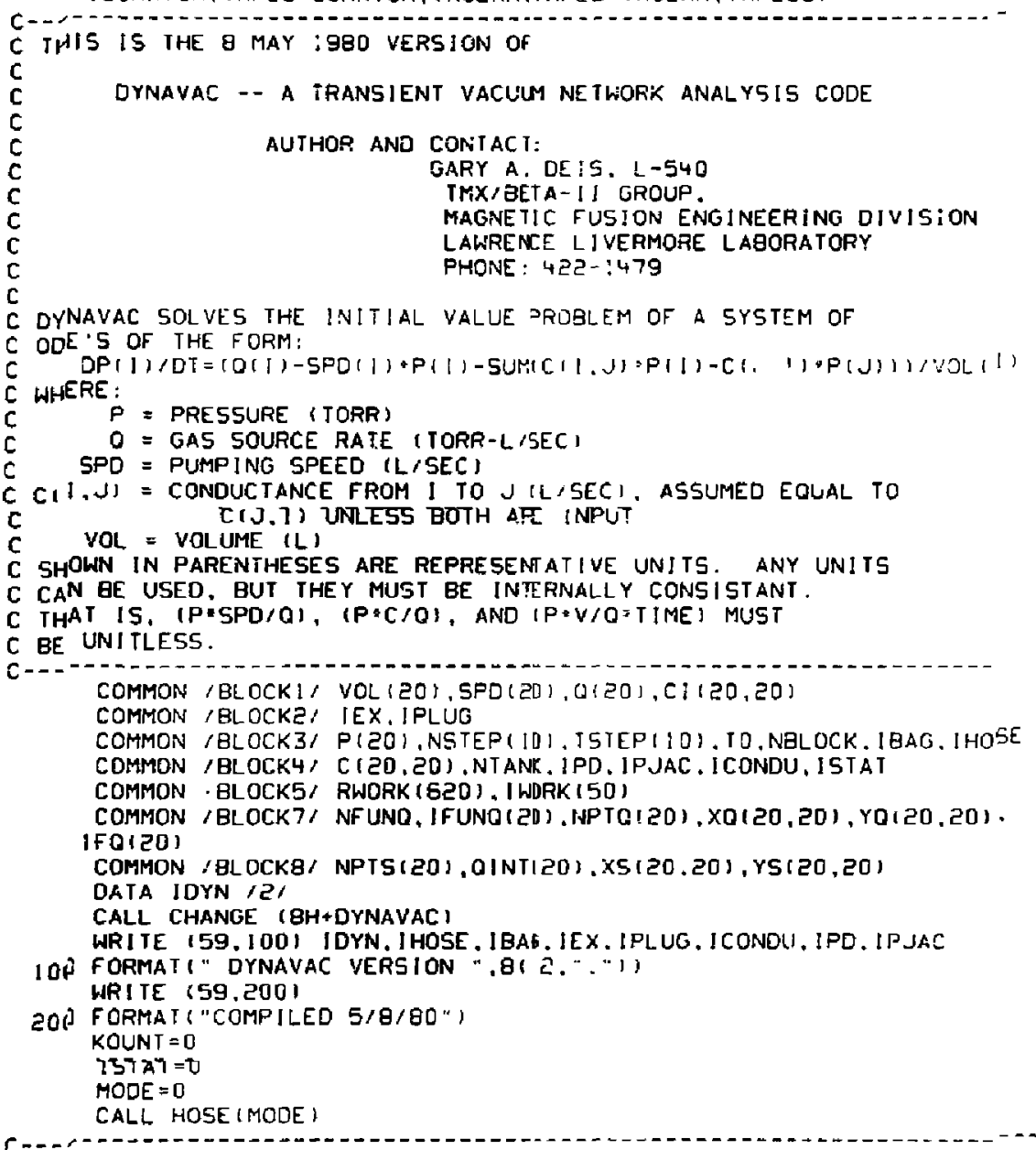

C SUBROUTINE hOSE HANDLES ALL INPUT.

C MODE = I SIGNALS DATA CHECK MODE.

C :STAT. LT. O AT ANY POINT SIGNALS AN ERROR

\section{CALL EMPTYIS)}

IF IMDDE. EQ. I ICALL EXIT

IF (ISTAT.LT.O) GO TO IO

CALL BAGIKOUNT)

C SUEPOUTINE BAG HANDLES THE ACTUAL SOLUTION, INCLUDING

C TIME STEPPING. ETC. KOUNT IS THE TOTAL NUMBER OF DATA

C POINTS OUTPUT BY BAT. 


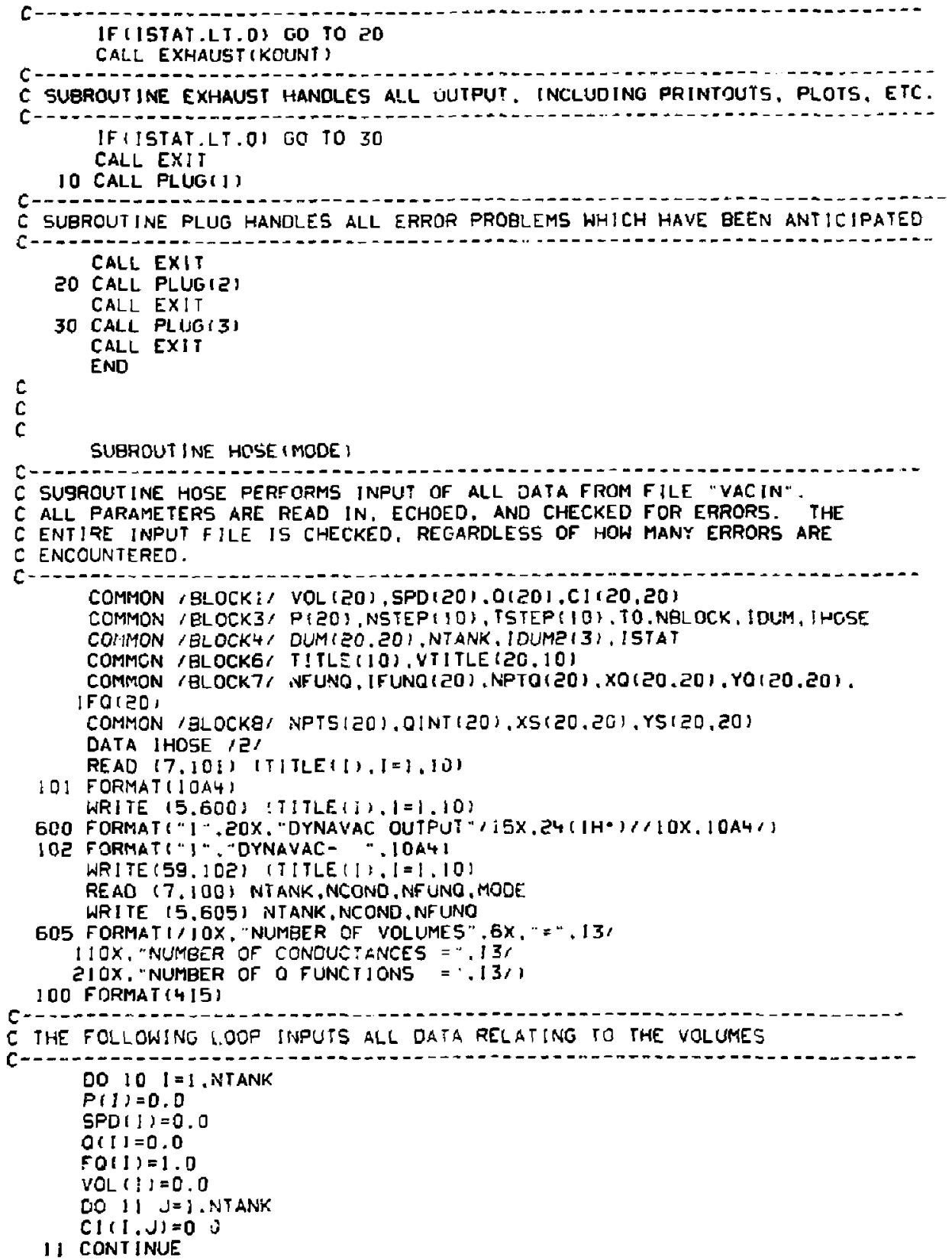




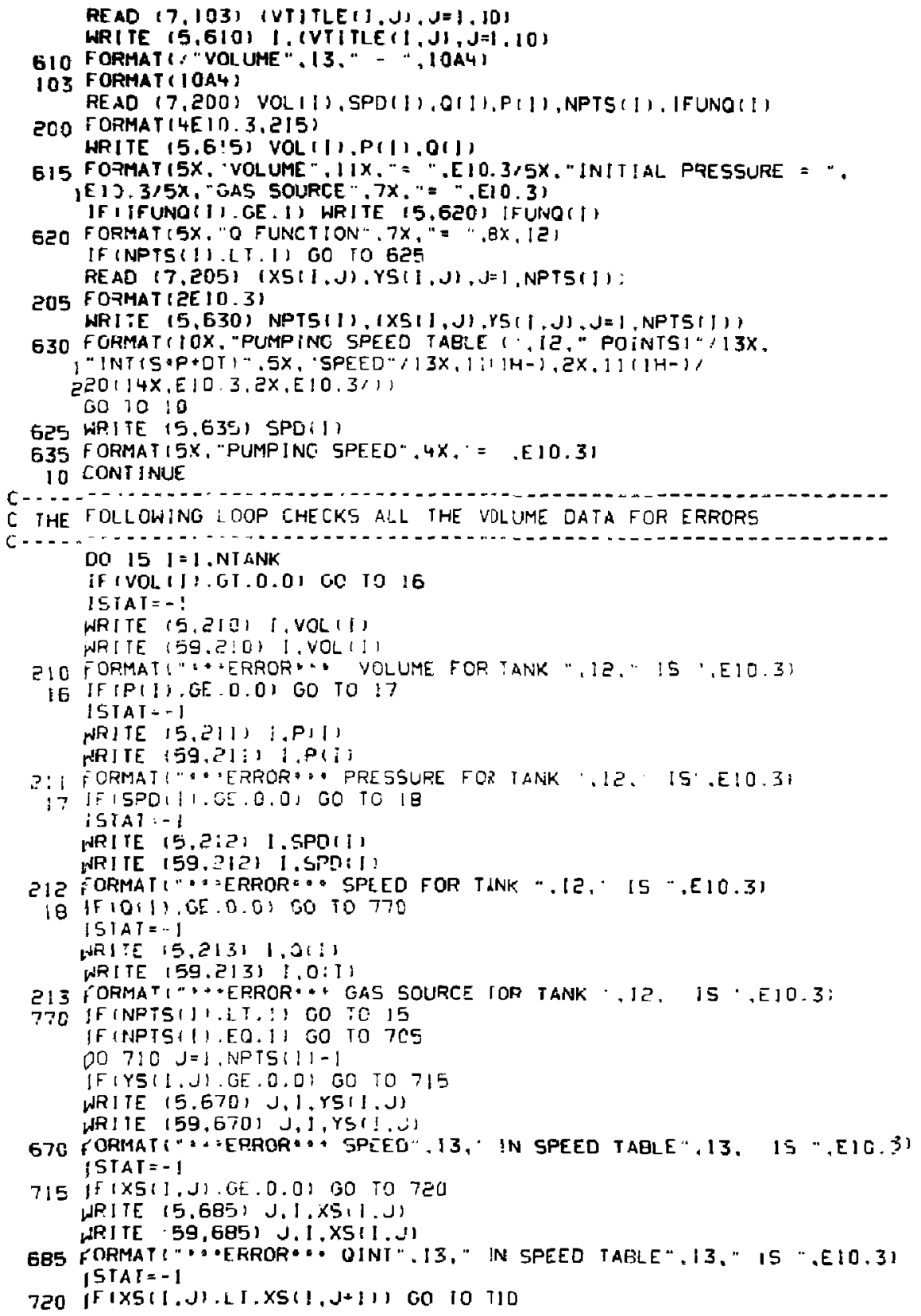




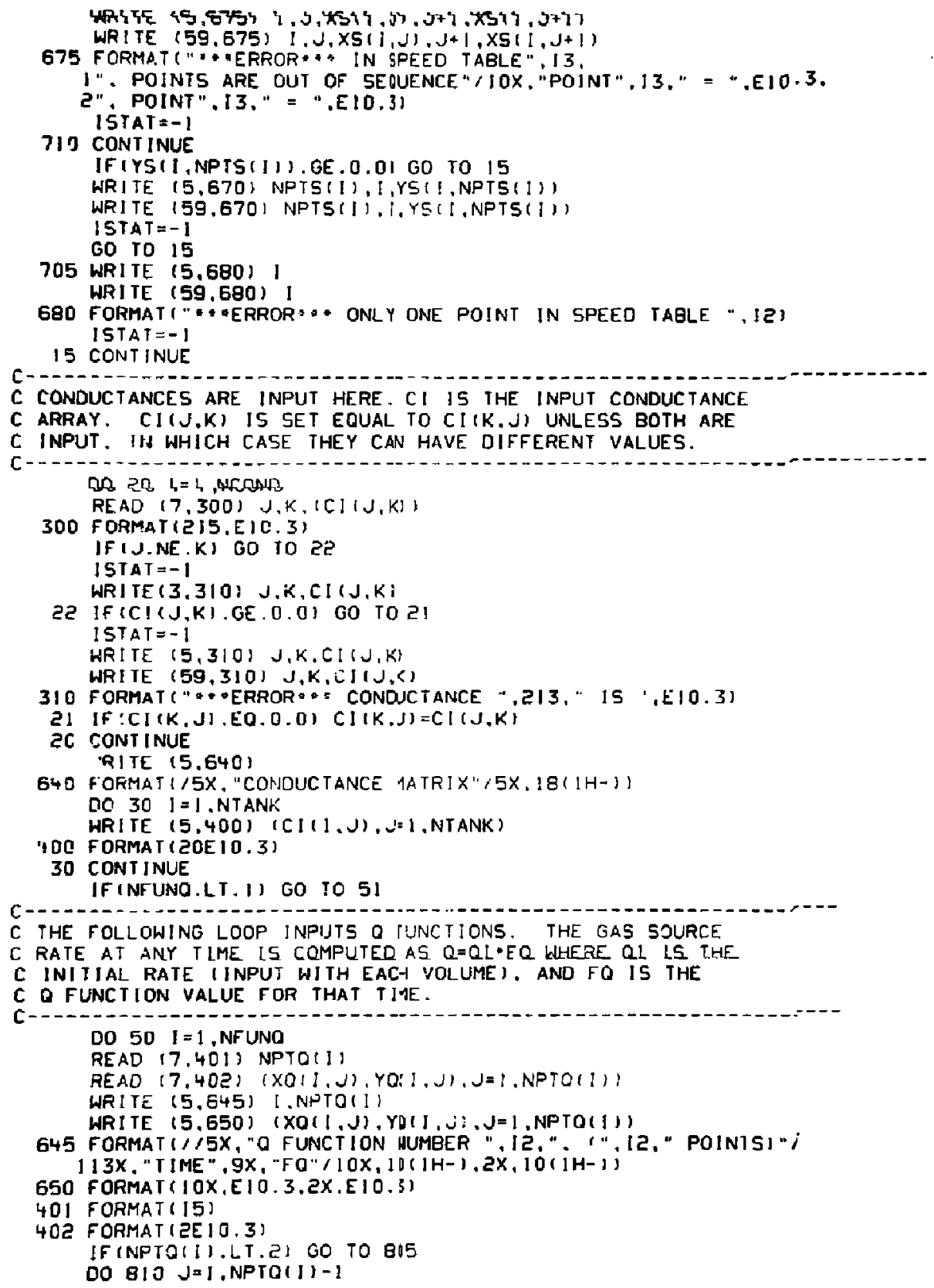




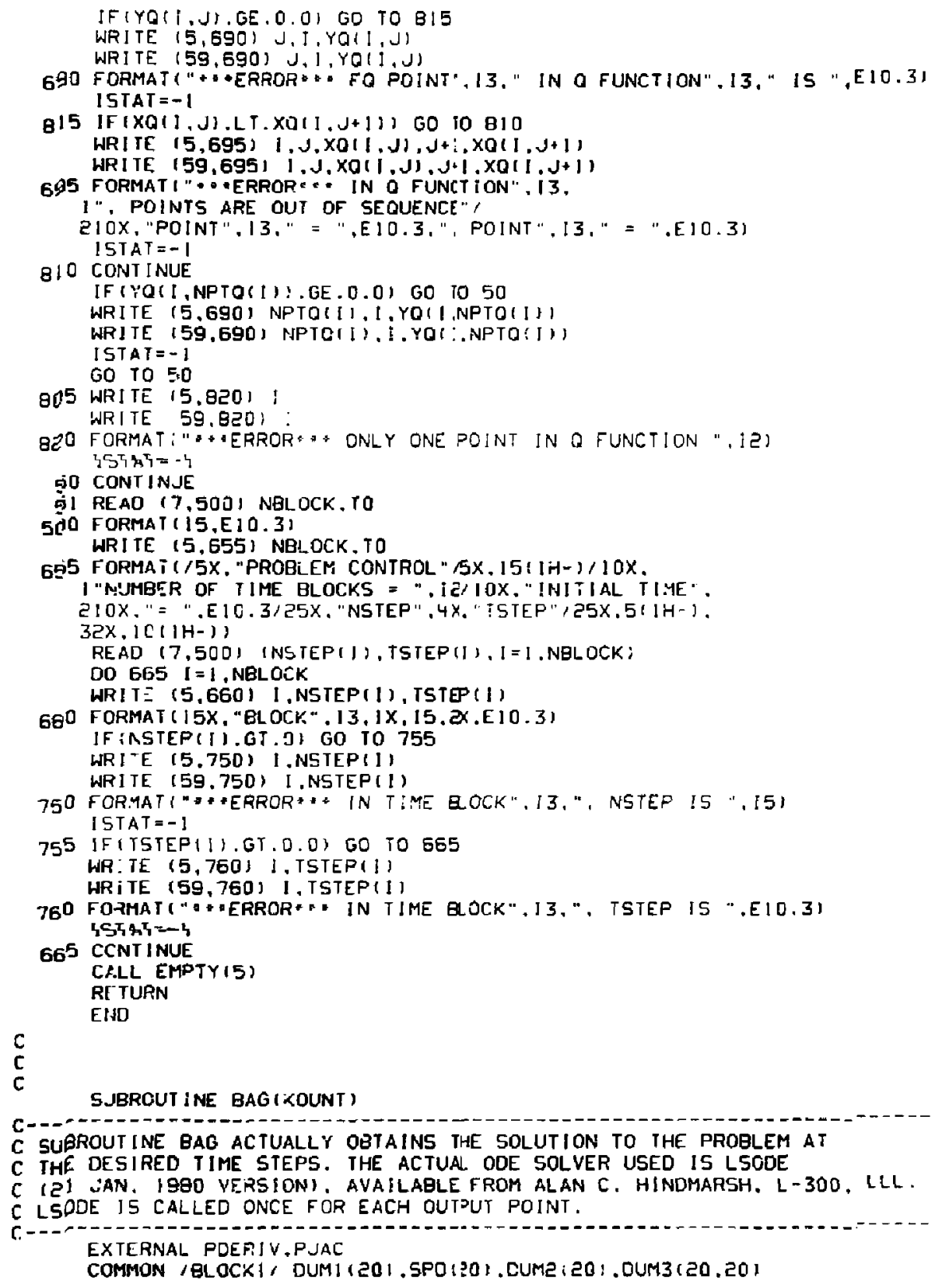




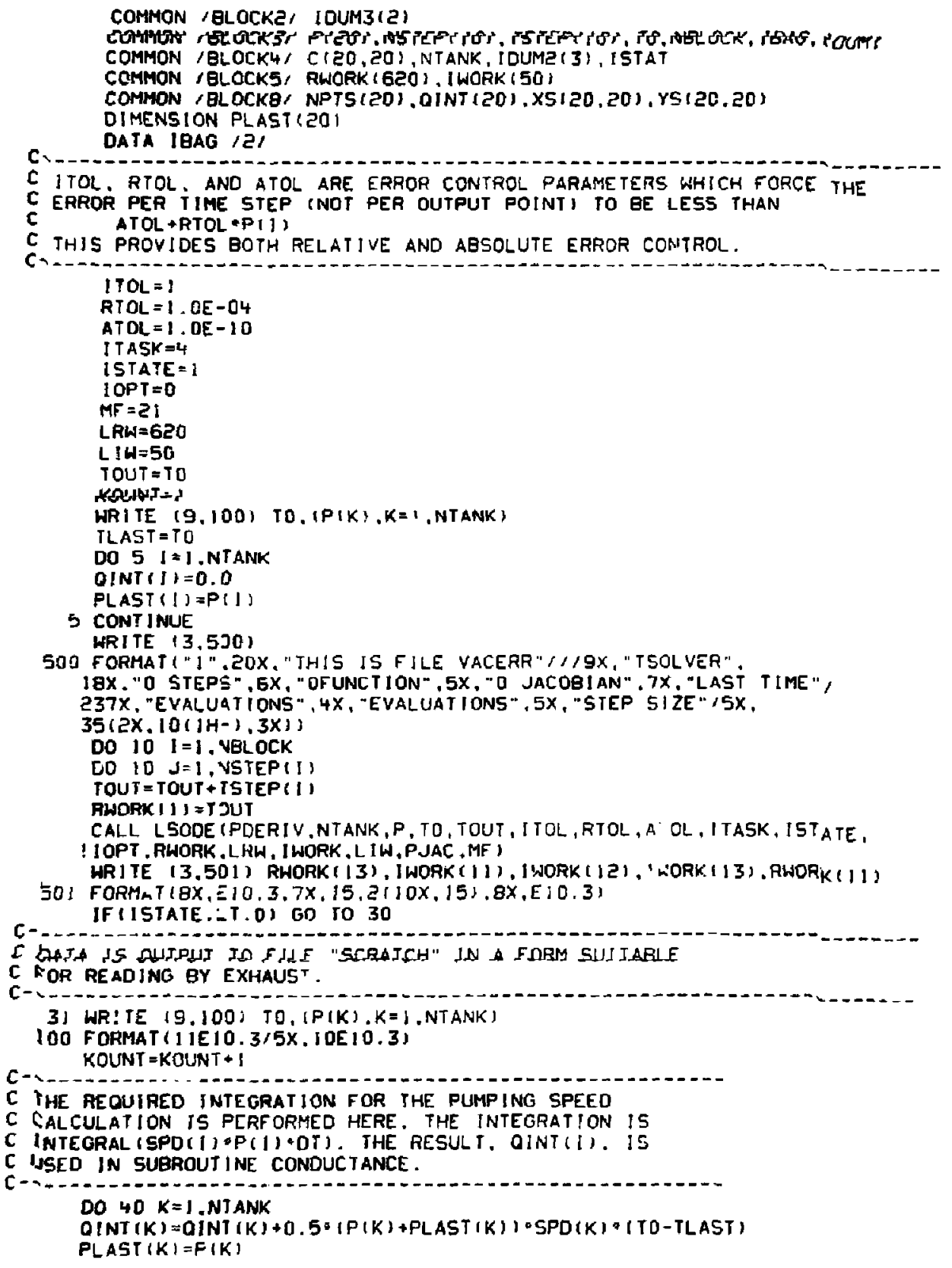


40 CONT INUE

TLAST FTO

10 CONT : NUE

CALL EMPTYISH

RETURN

30 ISTAT $=-1$

CALL EMPTYI 9

WRITE (3,502) ISTATE, TO

502 FORMAT " ISTATE $="$ I2,"AT T $=*$ E10.3 IF (ISTATE.LT. -I) RETURN ISTATE $=5$ GO TO 31 END

C

C

SUBRCUT INE EXHAUS I IKOUNT ?

C SUBROUTINE EXHAUST PERFORMS ALL OUTPUT FUNCTIONS.

C PRESSURE VS. TIME DATA IS READ FROM FILE "SCRATCH".

C FIRST. PLOTS ARE PRODUCEd FOR ALL VOLUMES at THE SAME SCALE.

C FIVE LINES PER PLOT. NEXT A PLOT IS MADE FOR EACH VOLUME,

C USING THE LARGEST POSSIBLE SCALE. IN ADDITION, PRINTED DATA

$C$ IS OUTPUT TO FILE VACPRT, 50 LINES TO A PAGE, WITH APPROPRIATE

$C$ HEADINGS AT THE TOP OF EACH PAGE.

C

DIMENSION TIIDOO), P(20, 1000), PPLOT (1000)

DIMENSION PMIN(20), PMAX(20)

COMMON /BLOCKE, IEX, IOUM

COMMON /BLOCK4, DUMI20,20), NTANK, IOUME (3), 15TAT

COMMON /BLCCKS/ RWORKISZO), (WORK (50)

COMMON /GLOCKE, TITLE(10), VTITLE(20,10)

DATA IEX $/ Z$ I

CALL REWJND(G)

DO $90 \quad[=1$, NTANKK

$P M I N I I]=1.0 E+50$

$P M A X[1]=0.0$

90 CONT INUE

WR ITE $(5,304)$ IT ITLE (1). 1 =1.10?

104 FQRMAT/"1" "DYNAVAC - ". 10A4/,

WR!TE $(5,105) \quad(I, I=1, N$ TANK)

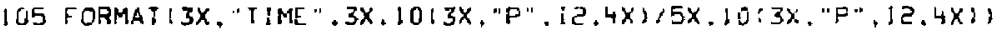
I KCUNI $=0$

C DATA IS READ IN FROM FILE "SCRATCH" ANO LOAOED INTO

$C$ ARRAY $P$. THE FIRST SUESCRIPT IS THE VOLUME NUMEER.

C AND THE SECOND IS THE TIME STEP NUMBER (TQ=STEP)?.

¿ PRINTEO DATA IS OUIPUT TO FILE "VACPRT"

C......... D.

DO $10 \quad 1=1$, KOUNT

READ 19,100$) T(1),(P(\lambda, 1), J=1, N T A N K)$

100 FORMAT ( IIE $10.3 / 5 \times, 10 E(0,3)$

WRITE $[5,100] T(1),(P I J, 1), J=1$, NTANK)

IKOUNT $=$ IKOUNT +1

IF(IKOUNT.LT.5O) GO TO 15

WR T TE $\{5,104\}$ (IITLE $(K), K=1,10)$

WRI TE $(5,105] \quad[K, K=1$. NTANK I

I KOIJNT $=0$

C MAXIMUM AND MINIMUM PRESSURE FCR EACH VOLUME IS LOCATED. 
C AS hELL AS THE MAXIMUM AND MINIMUM FOR ALL VOI_UMES (PMAXY

C AND PMJNXJ. THESE ARE USED FOR SCALING PURPOSES.

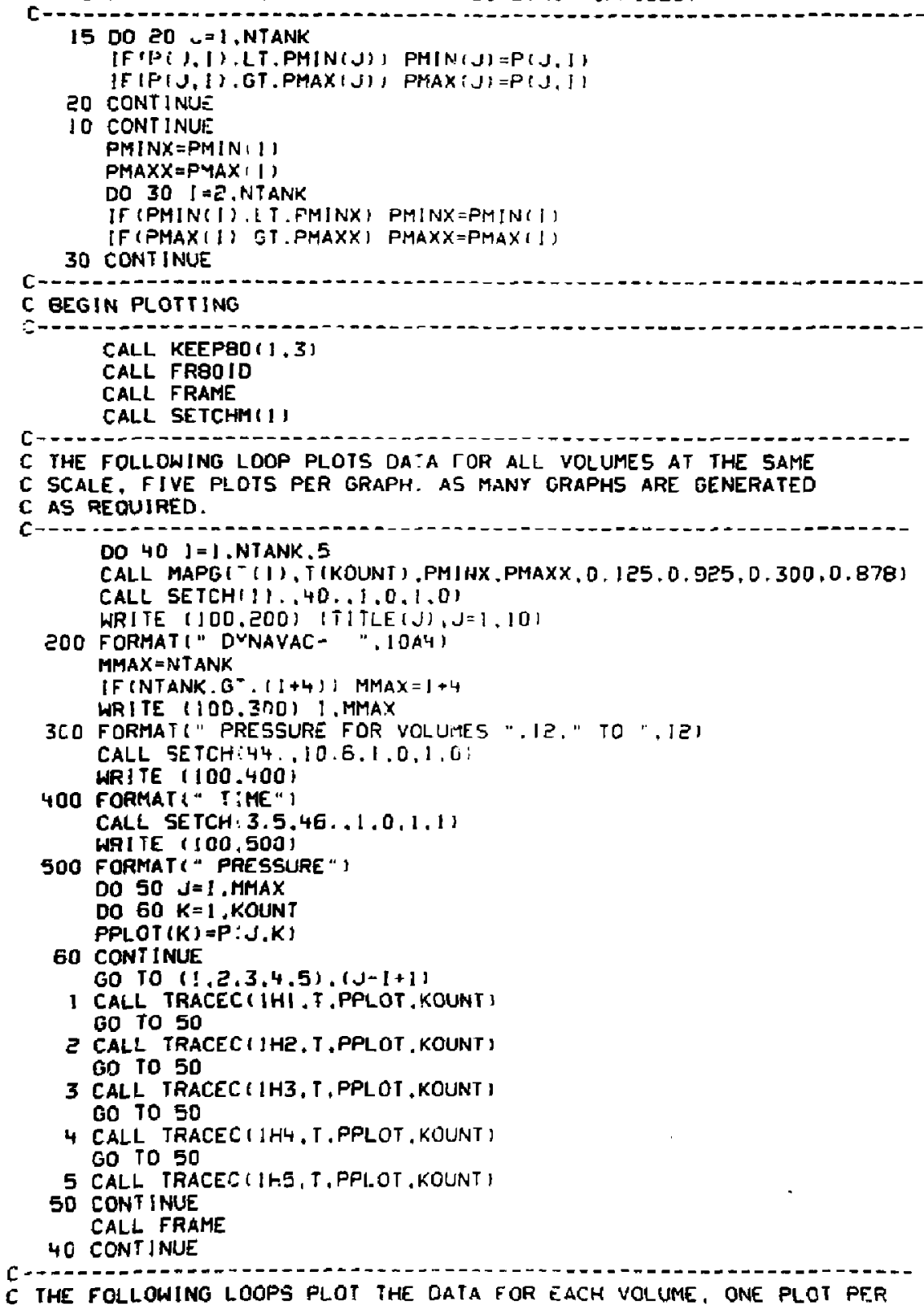

1 CALL TRACECIIHI. F. PPLOT, KOUNT GO TO 50

2 CALL TRACECI IHE, T.PPLOT . KOUNT ) GO TO 50

3 CALL TRACEC : $1 \mathrm{H3}, \mathrm{T}$,PPLOT, KOUNT I GO TO 50

4 CALL TRACECIIH4, T, PPLOT, KOUNT : GO TO 50

5 CALL TRACEC ( I F, T, PPI.OT, KOUNT )

50 CONTINUE CALL FRAME

40 CONTINUE

C THE FOLLOWING LOOPS PLOT THE DATA FOR EACH VOLUME, ONE PLOT PFR 


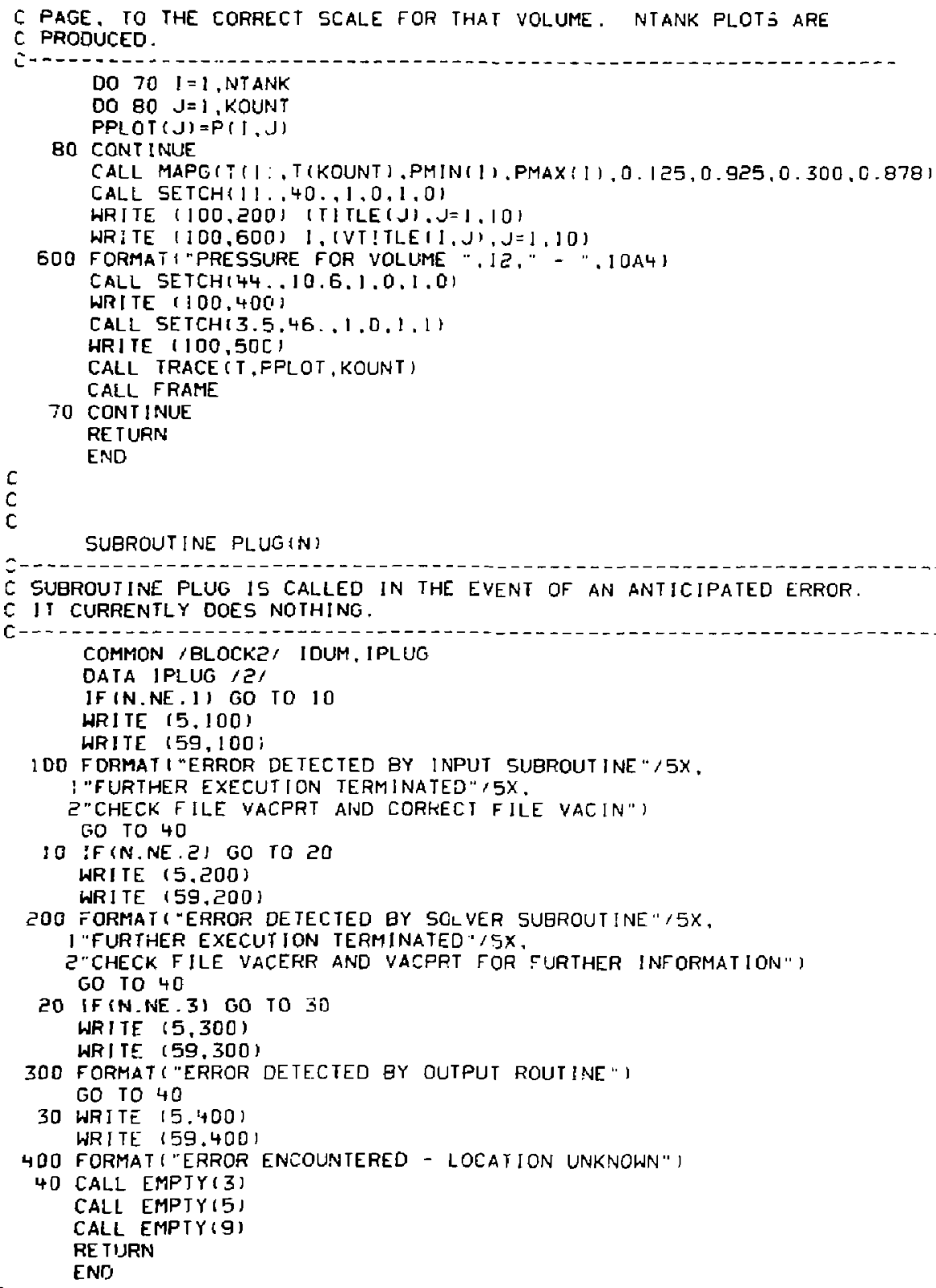




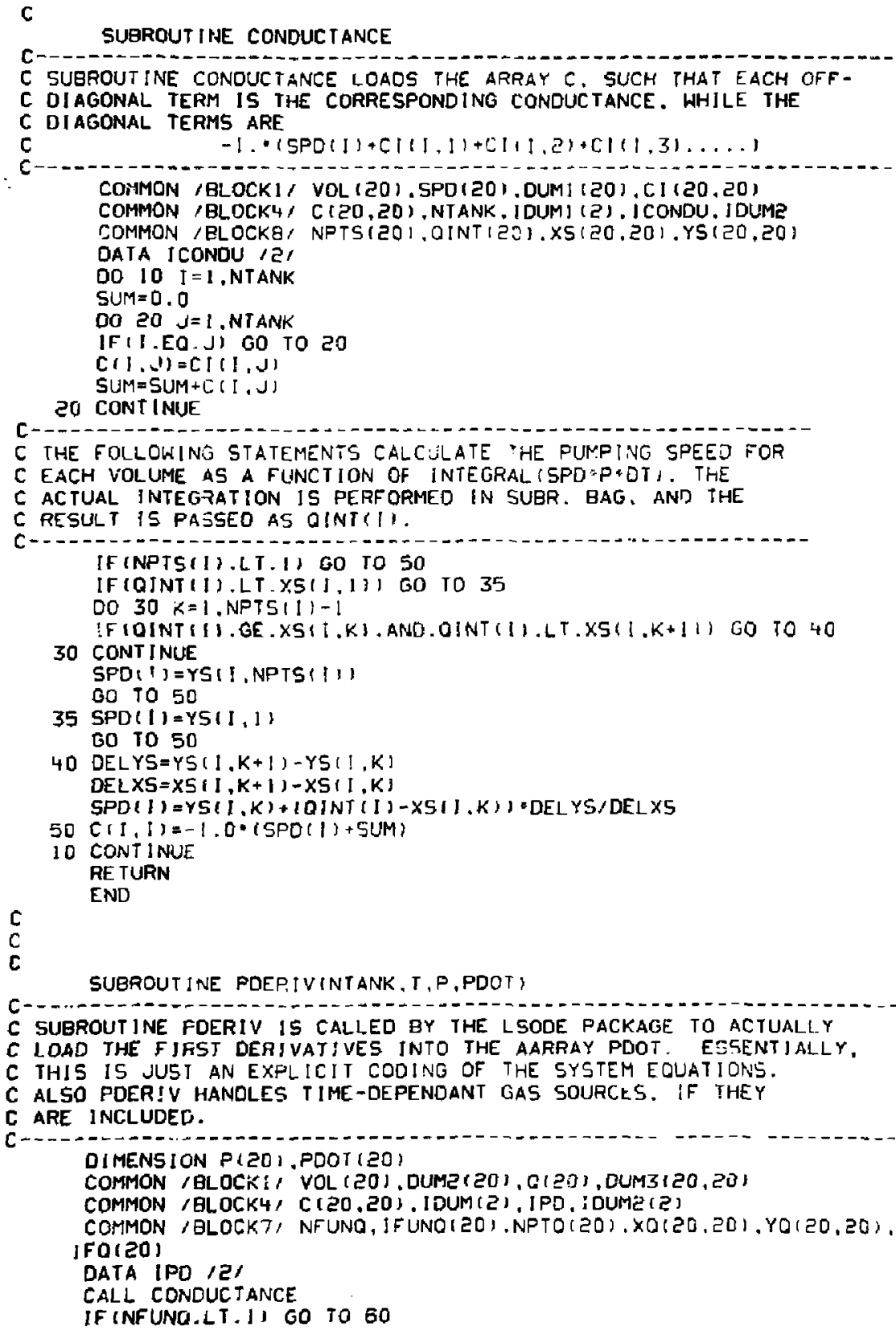




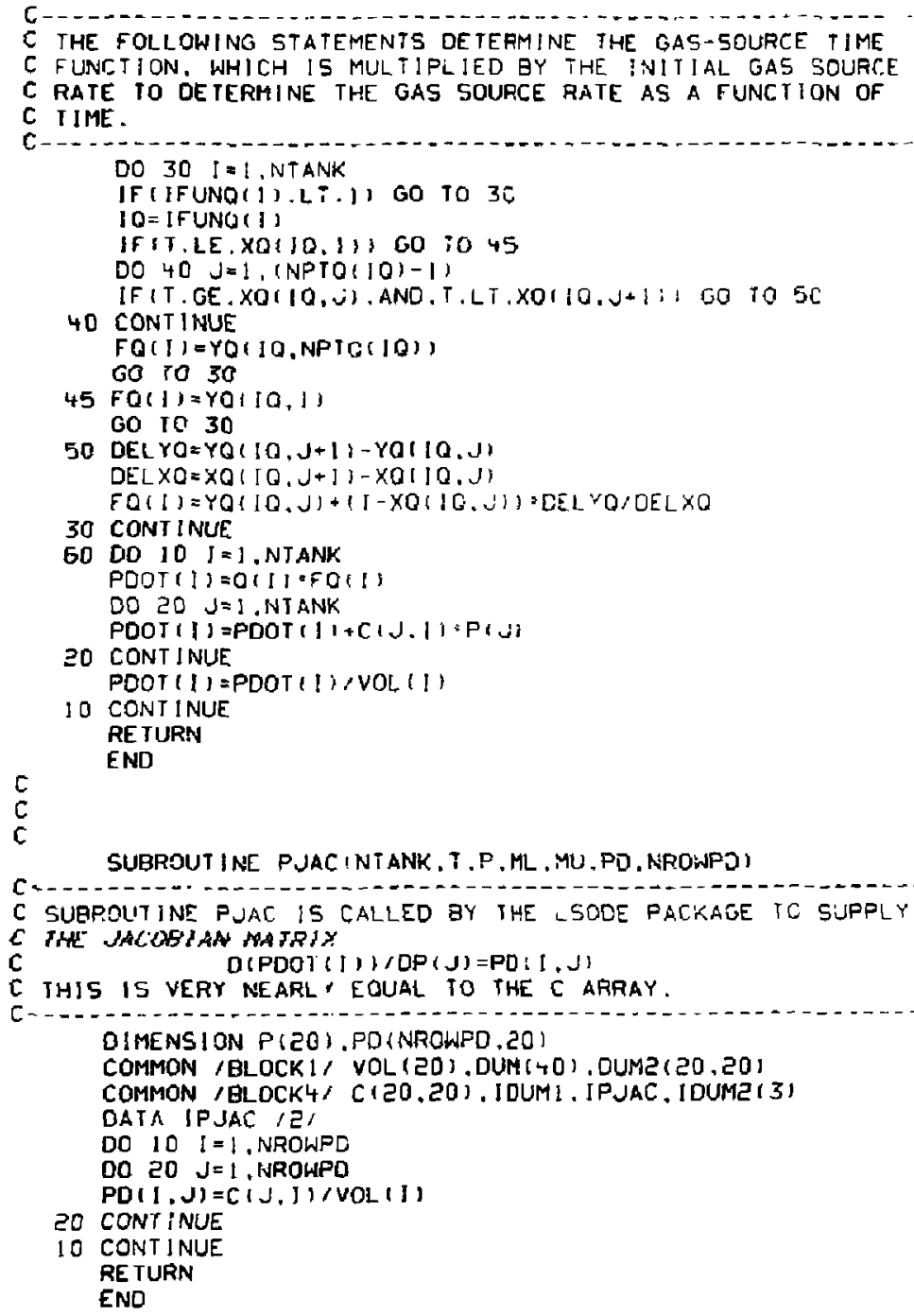




\section{ACKNOWLEDEMLNTS}

The author gratefully acknowlesges the assistance and suggestions of Robert Wong, R. Paul Drake, and especially Mike Richardson, all of whom supplied direction and useful suggestions during the conception and writing of DYNAVAC. 